27. 6. 2012

\title{
Ambient pressure x-ray photoelectron spectroscopy during electrochemical promotion of ethylene oxidation over a bimetallic Pt-Ag/YSZ catalyst
}

\author{
Arafat Toghan ${ }^{1}$, Rosa Arrigo ${ }^{2}$, Axel Knop-Gericke ${ }^{2}$, Ronald Imbihl ${ }^{1 *}$ \\ ${ }^{1}$ Institut für Physikalische Chemie und Elektrochemie, Universität Hannover, \\ Callinstrasse 3-3a, D-30167 Hannover, Germany \\ 2 Fritz-Haber-Insititut der Max-Planck Gesellschaft, Abteilung Anorganische Chemie, \\ Faradayweg 4-6, D-14195 Berlin, Germany
}

\section{Abstract:}

The electrochemical promotion of the $\mathrm{C}_{2} \mathrm{H}_{4}+\mathrm{O}_{2}$ reaction over a bimetallic $\mathrm{Pt} / \mathrm{Ag}$ catalyst (Pt:Ag ratio $\approx 1.5$ ) interfaced to yttrium stabilized zirconia (YSZ) has been studied at 0.25 mbar and $\mathrm{T}=650 \mathrm{~K}$ using X-ray photoelectron spectroscopy as in situ method. Applying a positive potential of $2 \mathrm{~V}$ causes a relative rate increase in the $\mathrm{CO}_{2}$ production up to $120 \%$; the electrocatalytic promotion effect is non-Faradaic $(\Lambda \approx 2)$. An electrochemical promotion is found to occur only at high enough $\mathrm{p}\left(\mathrm{C}_{2} \mathrm{H}_{4}\right)$ when a carbonaceous $\mathrm{CH}_{\mathrm{x}}$ layers builds up inhibiting $\mathrm{O}_{2}$ adsorption. The $\mathrm{CH}_{\mathrm{x}}$ film is estimated to be about 5-6 layers thick. Only at low $\mathrm{p}\left(\mathrm{C}_{2} \mathrm{H}_{4}\right)$ the application of an electric potential causes a decrease in the carbon signal associated with a growth of the $\mathrm{O} 1 \mathrm{~s}$ signal at $529.3 \mathrm{eV}$. The latter species can be assigned to an electrochemically generated oxygen spillover species at Ag sites.

Keywords: yttrium stabilized zirconia (YSZ), Pt/Ag catalyst, ethylene oxidation, electrochemical promotion, oxygen spillover, x-ray photoelectron spectroscopy (XPS)

*Corresponding author. E-mail address: imbihl@pci.uni-hannover.de 


\section{Introduction}

An electrochemical promotion of heterogeneously catalyzed reactions (EPOC) can be achieved with porous thin film electrodes interfaced to a solid electrolyte [1-5]. Upon application of an electric potential to the electrodes a reaction which is catalyzed by the metal may be strongly enhanced. Pioneered by Vayenas et al. the EPOC effect has been demonstrated for about 100 reaction systems comprising a vast range of different reactions, catalytic metals and different solid electrolytes such as the $\mathrm{O}^{2-}$ conducting yttrium stabilized zirconia (YSZ) and the $\mathrm{Na}^{+}$conducting $\beta^{\prime \prime}-\mathrm{Al}_{2} \mathrm{O}_{3}$ [2-5]. Typically, the electrochemically induced rate increase is non-Faradaic with respect to the ionic current. The interface Pt/YSZ has also received considerable interest in connection with the performance of solid oxide fuel cells [6].

Mechanistically, the electrochemical promotion effect could be traced back to the spillover of the transported ionic species from the three-phase-boundary (tpb) metal/solid electrolyte/gas phase where it is discharged onto the surface of the metal electrode $[4,5,7,8]$. Despite a large body of empirical data fundamental questions still remain unresolved [5,9]. One open question is that after the identity of the oxygen spillover species in the system $\mathrm{Pt} / \mathrm{YSZ}$. A special spillover species $\mathrm{O}^{\delta-}(\delta \approx 2)$ with properties different from regular chemisorbed oxygen on Pt has been postulated by Vayenas et al. [3,4,10]. While low pressure $\left(10^{-6}-10^{-10}\right.$ mbar) experiments with Pt/YSZ model catalysts unambiguously demonstrated that the spillover species is identical with regular chemisorbed oxygen [7], it remains open whether or not such a special spillover species develops at higher pressure. A second issue discussed controversely in the literature is the origin of the non-Faradaic behavior in EPOC experiments. A "sacrificial promoter mechanism" based on the existence of a special spillover oxygen species was postulated by Vayenas et al. [3,4] Alternatively, an ignition mechanism has been proposed by Toghan et al. [9,11,12]. The ignition mechanism does not require a special oxygen spillover species and instead assigns the spillover species the role of triggering the reactive removal of an inhibitory adlayer. A third possibility has been introduced earlier by Sobyanin et al. who suggested that an electrochemically initiated chain mechanism might be responsible for the non-Faradaic rate increase [13-15].

Most of the difficulties in coming to a clear mechanistic picture of the EPOC effect can be traced back to the well known pressure and material gap in heterogeneous catalysis. Nearly all of the EPOC studies have been conducted in the mbar to atmospheric pressure range with structurally and chemically badly defined catalysts. A small number of surface science type 
studies have been conducted but what is completely missing are high pressure studies characterizing the state of the catalyst with in situ techniques $[5,16,17]$. For this reason we use here a differentially pumped x-ray photoelectron spectrometer with which in situ XPS experiments are feasible up to $\approx 1$ mbar. The reaction system we investigate is catalytic ethylene oxidation with $\mathrm{O}_{2}$ on a bimetallic Pt-Ag/YSZ catalyst. In preceding studies we investigated the $\mathrm{C}_{2} \mathrm{H}_{4}+\mathrm{O}_{2}$ reaction on $\mathrm{Pt} / \mathrm{YSZ}$ in an UHV environment using photoelectron emission microscope (PEEM) as main method [11,12]. This reaction system played a kind of paradigmatic role in the EPOC studies because it exhibited the strongest non-Faradaic effect of all reaction systems investigated so far $[18,19]$. Ag is used as catalyst for the epoxidation of ethylene. For both separate systems, Pt/YSZ and Ag/YSZ the electrochemically induced oxygen spillover has been characterized by XPS under low pressure conditions $[7,8,20]$.

The electrocatalytic behavior of bimetallic electrodes was shown recently to exhibit quite favorable properties with respect to hydrazine oxidation where a non-Faradaic pathway indicating EPOC behavior was found [21]. The question we address here is whether the presence of two metals leads to new unexpected results with respect to spillover and electrochemical promotion or whether the two metals just act independent of each other so that the resulting behavior is just a superposition of the known behavior of each of the two metals. As will be shown the two metals largely retain their individual properties in this electrochemical experiment.

\section{Experimental}

\section{$\underline{\text { Samples and electrochemical set-up }}$}

For the preparation of the sample we used a square-shaped (111) oriented YSZ single crystals (13 mol\% yttrium, MaTeck $\mathrm{GmbH}$, Germany) with a thickness of $1.5 \mathrm{~mm}$ and of the dimensions $16 \times 16 \mathrm{~mm}^{2}$. Only one side was polished with a surface roughness $<0.5 \mathrm{~nm}$. The counter $(\mathrm{CE})$ and the reference electrodes $(\mathrm{RE})$ were prepared with Pt paste on the unpolished side of the YSZ substrates followed by calcination at $1120 \mathrm{~K}$ in air for several hours $(\approx 9 \mathrm{~h})$ in order to remove the organic compounds. The working electrode (WE) was prepared on the polished side of single crystal YSZ (111) in two stages. Firstly, Pt and Ag were codeposited by sputtering onto YSZ substrates in an inert atmosphere $\left(\mathrm{p}(\mathrm{Ar})=2 \times 10^{-2} \mathrm{mbar}\right)$ at $300 \mathrm{~K}$. The sputter deposition was followed by annealing in air at $1120 \mathrm{~K}$ for $3 \mathrm{~h}$. In order to obtain a metal film with high enough electric conductivity, in a second step a thin coating of Pt paste (A1118 Demetron) was deposited with a brush followed by annealing in air at $1120 \mathrm{~K}$ for $3 \mathrm{~h}$. 
As shown by XPS, the Ag segregates to the surface of the Pt film forming a Pt/Ag alloy (see below). The morphology of the Pt/Ag WE after sintering in air for $3 \mathrm{~h}$ at $1123 \mathrm{~K}$ was investigated by scanning electron microscopy (SEM, JEOL JSM-6700F) and by surface profilometer (Veeco Dektak 6M stylus). A porous network film with a thickness on the order of a few $\mu \mathrm{m}$ was obtained (see Fig. S1 in Supporting Information). X-ray diffraction (XRD) of the Pt-Ag film turned out to be identical to the pure Pt film [22].

For the electrochemical measurements a standard three-electrode set-up was used as displayed in Fig. 1 with a potentiostat controlling the potential of the working electrode (WE) with respect to a reference electrode. Under high pressure conditions $(0.1-1 \mathrm{mbar})$ there is practically no difference between the potentials of the CE and the RE vs. the WE; at low pressure and, in particular under UHV conditions, the difference can reach up to several Volt. Since no gas reference electrode was used the potential of the reference electrode is not fixed but may shift due to zirconia reduction at the interface YSZ/Pt reference electrode. As discussed in detail in ref. 23 the measured potentials depend also on the cell geometry i. e. upon dimensions and lay-out of the electrodes because these geometric factors will control the current distribution. In our case, we do not explicitly calculate the error which is potentially introduced by the geometry because the main uncertainty in the measured potentials is caused by not working with a reference electrode with fixed potential.

\section{$\underline{\text { XPS and data analysis }}$}

The XPS experiments were performed using the monochromatized radiation of the ISSIS beamline at the synchrotron facility BESSY II of the HZB in Berlin. A specially designed differentially pumped XPS system was used [24]. Details of the reaction cell and the differentially electrostatic lens system are described elsewhere [25]. X-rays were admitted to the experimental cell through a 50 -nm-thick $\mathrm{Si}_{3} \mathrm{~N}_{4}$ window. The photoelectrons, emitted under normal emission, entered a differentially pumped electrostatic lens system and were focused on the entrance slit of a standard electron energy analyzer, where high vacuum conditions were maintained by an additional pumping stage. This setup allowed a variation of the total pressure in the reaction cell between $10^{-7}$ and 0.5 mbar.

As indicated in Fig.1a, the working electrode is at ground potential and all binding energies are therefore referenced to the Fermi level of the working electrode. The excitation (photon energy) for Pt4f, C1s, Ag3d and O1s core level spectra were 220, 435, 518 and $680 \mathrm{eV}$, respectively, resulting in the same high surface sensitivity with an inelastic mean free path (IMFP) of the photoelectrons of about $0.86 \mathrm{~nm}$ in carbon and $0.4 \mathrm{~nm}$ in platinum [26]. The 
Pt4f, Ag3d, C1s and O1s envelopes were fitted using Casa XPS software after subtraction of a Shirley background [27,28]. The fitting of the spectra was done with Gaussian-Lorentzian functions fixing the peak position within $\pm 0.1 \mathrm{eV}$.

The spectra have been normalized to the impinging photon flux that has been determined by a cleaned $\mathrm{Au}$ foil and corrected for the fraction of higher order of the monochromator and the electron current in the storage ring. Quantitative XPS data analysis was performed assuming homogeneous model distribution of the elements using theoretical cross sections according to the following equation [29]:

$$
\mathrm{I}_{\mathrm{A}}^{*}=\mathrm{I}_{\mathrm{A}} /\left(\text { o.r. } \mathrm{n}_{\gamma}\right)
$$

where $I_{A}$ is the measured intensity and $I_{A}^{*}$ the normalized intensity of species $A$; $\sigma$ is the theoretical cross section, $r$ is the ring current in $\mathrm{mA}$ and $\mathrm{n}_{\gamma}$ is the number of photons per $\mathrm{mA}$ ring current (photon flux). Correcting for the different photoionization cross sections one calculates a Pt:Ag ratio of 1.5 assuming a homogeneous mixture of the two components in the alloy.

The abundance $\mathrm{C}_{\mathrm{X}}$ was obtained as:

$$
\mathrm{C}_{\mathrm{X}}=\frac{\mathrm{I}_{\mathrm{X}}^{*}}{\sum_{\text {allY }} \mathrm{I}_{\mathrm{Y}}^{*}} \cdot 100
$$

The abundance calculated in this way is a rough approximation because one assumes a homogeneous mixing of the elements $(\mathrm{Pt}, \mathrm{Ag}, \mathrm{C}, \mathrm{O}$ and $\mathrm{Si})$ in the probed surface region $(\approx 10$ layers) which typically is not the case. The thickness of the carbon overlayer was determined by applying the exponential attenuation by overlayer model according to the following equation [30]:

$$
\mathrm{I}_{\mathrm{C}}^{*} / \mathrm{I}_{\mathrm{S}}^{*}=\left(1-\mathrm{e}^{(-\mathrm{t} / \lambda \mathrm{C})}\right) / \mathrm{e}^{-\mathrm{t} / \lambda \mathrm{S}}
$$

where $\mathrm{t}$ is the overlayer thickness, $\mathrm{I}_{\mathrm{C}}^{*}$ is the normalized intensity of the carbon overlayer and $\mathrm{I}_{\mathrm{S}}^{*}$ is the normalized intensity of the Pt substrate. The inelastic mean free path (IMFP) for C1s and Pt4f at $150 \mathrm{eV}$ kinetic energy are denoted as $\lambda_{\mathrm{C}}$ and $\lambda_{\mathrm{S}}$, respectively. For expressing the thickness in number of monolayers the interplanar spacing of graphite of $0.34 \mathrm{~nm}$ was taken [31].

\section{$\underline{\text { Reaction experiments }}$}


Under reaction conditions, the cell was operated as a continuous flow reactor. Gases were introduced via mass flow controllers. Reaction products were monitored with a differentially pumped quadruple mass spectrometer (QMS). The YSZ sample was heated from the backside through a 100-nm-thick SiC window with an infrared laser. The sample temperature was measured via a $\mathrm{K}$-type $\mathrm{Ni} / \mathrm{NiCr}$ thermocouple spotwelded to the $\mathrm{WE}$ on the front side of the sample. All experiments were conducted at $\mathrm{T}=650 \mathrm{~K}$. The choice of this temperature was motivated by two limiting cases. At a temperature below $600 \mathrm{~K}$ the ionic conductivity of YSZ becomes too low to generate spillover oxygen and beyond $650 \mathrm{~K}$ no electrochemical promotion effect was observed in the $\mathrm{YSZ} / \mathrm{Pt} / \mathrm{C}_{2} \mathrm{H}_{4}+\mathrm{O}_{2}$ system [32].

Prior to the experiments the Pt film was cleaned by repeated cycles of mild Ar+ ion bombardment $\left(\mathrm{t}=20 \mathrm{~min}, \mathrm{E}=1.5 \mathrm{keV}, \mathrm{p}(\mathrm{Ar})=1 \mathrm{x} 10^{-4} \mathrm{mbar}\right)$. After repeated cycles of cleaning the photoemission spectra indicated as only remaining contaminants $\mathrm{Si}(\approx 2 \%)$ and oxygen (Fig. S2 in Supporting Information). The reaction system was investigated at $650 \mathrm{~K}$ keeping the total pressure fixed at 0.25 mbar and varying the ratio of the gases in the $\mathrm{C}_{2} \mathrm{H}_{4} / \mathrm{O}_{2}$ mixture. The spectral regions of $\mathrm{Pt} 4 \mathrm{f}, \mathrm{Ag} 3 \mathrm{~d}, \mathrm{O} 1 \mathrm{~s}$ and $\mathrm{C} 1 \mathrm{~s}$ were recorded under reaction condition. Blank experiments without the catalyst showed no catalytic contribution from SiC. For back ground subtraction of the reaction rate the experiments with the Pt-Ag/YSZ sample were repeated at room temperature. The background production of $\mathrm{CO}_{2}$ at 300 is less than $1 \%$ of the $\mathrm{CO}_{2}$ production rate at $650 \mathrm{~K}$.

\section{Results}

\subsection{Surface characterization}

XP spectra of the bimetallic working electrode under operating conditions i.e. under open circuit $(\mathrm{OC})$ conditions and with an electric potential $\mathrm{V}_{\mathrm{WR}}=2 \mathrm{~V}$ applied are displayed in Fig. 2. At a 10:1 ratio $\mathrm{p}\left(\mathrm{C}_{2} \mathrm{H}_{4}\right) / \mathrm{p}\left(\mathrm{O}_{2}\right)$ the surface is covered by a thick layer of carbonaceous $\mathrm{CH}_{\mathrm{x}}$ species. The Pt4f spectrum in Fig. 2a displays besides the main component peak with a $\mathrm{Pt}_{4} \mathrm{f}_{7 / 2}$ signal at $71 \mathrm{eV}$ a second smaller component shifted by $0.90 \mathrm{eV}$ to higher binding energy (BE). Since the shift of this higher-lying component is less than $1 \mathrm{eV}$ it cannot be assigned to Pt oxide, but it may result from a local surface oxides e. g. at step edges or from the surface core level shift of Pt [33-38]. The corresponding Ag spectrum is reproduced in Fig. 2b. The Ag3d spectrum can be fitted with a single component but the BE of $\mathrm{Ag} 3 \mathrm{~d}_{5 / 2}$ of $367.71 \mathrm{eV}$ is shifted by $0.59 \mathrm{eV}$ to lower binding energy with respect to the $\mathrm{BE}$ of metallic $\mathrm{Ag}$ 
which lies at $368.3 \mathrm{eV}$. This shift is taken as evidence for alloy formation [39,40]. No changes in the $\mathrm{BE}$ of $\mathrm{Ag} 3 \mathrm{~d}$ are observed irrespective of whether an electric potential $\mathrm{V}_{\mathrm{WR}}=2 \mathrm{~V}$ is applied (see Fig. 2b), or whether the gas phase composition is changed (Fig. S3 in Supporting Information). In the Pt4f signal a small shift of $0.04 \mathrm{eV}$ to lower BE is seen upon applying an electric potential (Fig, S3). This shift is very small and could originate simply from an artifact, i. e. from some charging if not all parts of the WE electrode are in good electrical contact with each other.

\subsection{Kinetics}

The catalytic reaction leads almost exclusively to $\mathrm{CO}_{2}$ and $\mathrm{H}_{2} \mathrm{O}$ according to the following equations:

Open-circuit condition

$$
\mathrm{C}_{2} \mathrm{H}_{4}+3 \mathrm{O}_{2} \rightarrow 2 \mathrm{H}_{2} \mathrm{O}+2 \mathrm{CO}_{2}
$$

Closed-circuit condition

$$
\mathrm{C}_{2} \mathrm{H}_{4}+6 \mathrm{O}^{2-} \rightarrow 2 \mathrm{H}_{2} \mathrm{O}+2 \mathrm{CO}_{2}+6 \mathrm{e}^{-}
$$

Silver is a well known catalyst for epoxidation of ethylene yielding ethylene oxide as product [41]. Under our conditions we found no evidence for ethylene oxide as reaction product. Besides the main products $\mathrm{CO}_{2}$ and $\mathrm{H}_{2} \mathrm{O}$ only a small amount of $\mathrm{H}_{2}(\approx 2 \%$ of the total QMS signal) was detected; $\mathrm{CO}$ may also be a potential product but the $\mathrm{CO}$ signal at $\mathrm{m} / \mathrm{e}=28$ was hidden under the large main peak from ethylene. Fig. 3 displays the kinetics of ethylene oxidation for varying $\mathrm{p}\left(\mathrm{C}_{2} \mathrm{H}_{4}\right) / \mathrm{p}\left(\mathrm{O}_{2}\right)$ under open circuit $(\mathrm{OC})$ conditions and with an electric potential $\mathrm{V}_{\mathrm{WR}}=2 \mathrm{~V}$ applied. The experiment was conducted such that only the ratio of the two reactants was varied while the total pressure was always kept fixed at 0.25 mbar. First, for a chosen partial pressure ratio the stationary $\mathrm{CO}_{2}$ production under $\mathrm{OC}$ conditions was measured and then an electric potential was applied. For both cases the C1s, O1s Pt4f and Ag3d regions were recorded with XPS ( $\approx 60$ minutes per data point). Through measurements of the carbon signal (see below Fig. 5) it soon became evident that an accumulation of carbon on the surface takes place, i. e. measurements then no longer reflect a true stationary state of the system but a memory effect exists. In order to establish identical starting conditions therefore (starting from point IX in Fig. 5) the surface was exposed to pure $\mathrm{O}_{2}$ at $0.25 \mathrm{mbar}$ at $\mathrm{T}=650 \mathrm{~K}$ for several minutes prior to data taking.

The rate curves in Fig. 3a display the characteristic behavior with a reactive surface at low $\mathrm{p}\left(\mathrm{C}_{2} \mathrm{H}_{4}\right)$ and a poisoned state at high $\mathrm{p}\left(\mathrm{C}_{2} \mathrm{H}_{4}\right)$ which is well known from ethylene oxidation over Pt/YSZ $[11,12]$. At low $\mathrm{p}\left(\mathrm{C}_{2} \mathrm{H}_{4}\right)$ and a correspondingly low carbon coverage ethylene molecules can adsorb and react uninhibitedly and the rate increases roughly linearly 
with $\mathrm{p}\left(\mathrm{C}_{2} \mathrm{H}_{4}\right)$ (see Fig. 3b). Above a critical $\mathrm{p}\left(\mathrm{C}_{2} \mathrm{H}_{4}\right)$ value a substantial carbon coverage builds up inhibiting $\mathrm{O}_{2}$ adsorption and hence poisoning the catalytic surface. A relative maximum in the reaction rate marks this point. Beyond the rate maximum further increase of $\mathrm{p}\left(\mathrm{C}_{2} \mathrm{H}_{4}\right)$ has a negative effect on the rate due to a growing carbon coverage as shown in Fig. 3.

Applying a potential of $2 \mathrm{~V}$ causes an increase in catalytic activity, but this effect occurs only beyond the rate maximum. Before the rate maximum the electric potential has no effect on the rate as demonstrated by Fig. 3b. If one plots the relative rate increase vs. the partial pressure ratio one obtains the graph displayed in Fig. 4a in which the relative rate increase grows roughly linearly with the $\mathrm{C}_{2} \mathrm{H}_{4} / \mathrm{O}_{2}$ ratio. At a 10:1 ratio the electrochemically rate increase reaches $120 \%$. If one looks into the absolute rate increase visible in Fig. 3a then this increase is nearly constant between the $\mathrm{C}_{2} \mathrm{H}_{4} / \mathrm{O}_{2}$ ratios 2:1 and 10:1. The explanation for the different behavior of absolute and relative rate increase is simple. At high $\mathrm{p}\left(\mathrm{C}_{2} \mathrm{H}_{4}\right)$ the rate curve in Fig. $3 \mathrm{a}$ reveals that the $\mathrm{CO}_{2}$ production rate decays roughly with $1 / \mathrm{p}\left(\mathrm{C}_{2} \mathrm{H}_{4}\right)$. This results in an electrochemically induced relative rate increase which is first order in $\mathrm{p}\left(\mathrm{C}_{2} \mathrm{H}_{4}\right)$.

Compared to previous studies of ethylene oxidation over Pt/YSZ with $\mathrm{V}_{\mathrm{WR}}=2 \mathrm{~V}$ a higher pumping voltage had to be applied in order to cause a comparable increase in the reaction rate. Typically, only $1 \mathrm{~V}$ was used there and even at $1 \mathrm{~V}$ potential the electrochemically induced rate increase was already in saturation $[11,12]$. A plot of the rate increase vs. the applied potential in Fig. $4 \mathrm{~b}$ reveals that at $1 \mathrm{~V}$ practically no effect is seen here. The explanation for the different behavior lies presumably in the reference electrode whose potential is not fixed by a gas atmosphere with constant composition but floats depending on gas composition and on the degree of oxidation/reduction of the zirconia at the reference electrode. In addition, the different preparation of the sample might play a role [42]. Here the WE was prepared by Pt paste whereas in the earlier experiments a sputtered electrode was used.

\subsection{Variation of the surface composition during EPOC}

The variation of the $\mathrm{C} 1 \mathrm{~s}$ carbon signal during the EPOC experiment is shown in Fig. 5a. Under OC conditions some carbon is already present at very low $\mathrm{p}\left(\mathrm{C}_{2} \mathrm{H}_{4}\right)$ i.e. before the rate maximum. With increasing $\mathrm{p}\left(\mathrm{C}_{2} \mathrm{H}_{4}\right)$ the carbon signal rises rapidly and at the rate maximum the amount of carbon is already close to its maximum value. Upon further increasing $\mathrm{p}\left(\mathrm{C}_{2} \mathrm{H}_{4}\right)$ the carbon signal remains roughly constant until a $\mathrm{C}_{2} \mathrm{H}_{4} / \mathrm{O}_{2}$ ratio of 5 is reached and then starts to decrease by about $20 \%$. The variation of the Pt4f and of the Ag3d signals both 
normalized to $\mathrm{C} 1 \mathrm{~s}$ signal are displayed in Fig. 6. The dip we see in Fig. $5 \mathrm{~b}$ in the carbon layer thickness around a ratio $\mathrm{p}\left(\mathrm{C}_{2} \mathrm{H}_{4}\right) / \mathrm{p}\left(\mathrm{O}_{2}\right)=1.5$ is an artifact caused by an oxygen treatment applied to remove residual carbon from the Pt surface. A dip also shows up in Fig. 6 for the same reason.

The fitted $\mathrm{C} 1 \mathrm{~s}$ spectra recorded at $\mathrm{C}_{2} \mathrm{H}_{4} / \mathrm{O}_{2}$ ratios of 10:1 and 1:10, respectively, are reproduced in Fig. 7a and c. The effect of the applied potential on the C1s line shape is demonstrated in Fig. 7b, d, and e. As shown by Fig. 7c the C1s spectra recorded at low $\mathrm{C}_{2} \mathrm{H}_{4}$ partial pressure are well fitted with a main component centered at $284.3 \mathrm{eV}$ (Doniach-Sunjic line shape, $\mathrm{FWHM}=0.57 \mathrm{eV}$, asymmetric index 0.07). An additional component at $283.6 \mathrm{eV}$ is present too in a very small amount. The spectra recorded at higher $\mathrm{C}_{2} \mathrm{H}_{4}$ partial pressure are in general broader. The same fitting parameters were applied to fit all spectra independent of the $\mathrm{C}_{2} \mathrm{H}_{4} / \mathrm{O}_{2}$ ratio. As demonstrated by Fig. 7a the XP C1s core level spectra, recorded at high $\mathrm{C}_{2} \mathrm{H}_{4} / \mathrm{O}_{2}$ ratio, have been deconvoluted into three surface contributions $(\mathrm{C} 1-\mathrm{C} 3)$ plus a contribution from the gas phase (C4) centered at $283.6 \mathrm{eV}, 284.3 \mathrm{eV}, 284.75 \mathrm{eV}$ and $286 \mathrm{eV}$, respectively.

In agreement with previous investigations, the main component $\mathrm{C} 2$ at $284.33 \mathrm{eV}$ is assigned to $\mathrm{sp}^{2}$-bonded carbon $[43,44]$. Since this component represents a well ordered carbon structure it is less reactive toward oxidation and accordingly also persists in an excess of oxygen. Practically the same C1s BE of $284.3 \mathrm{eV}$ was reported by Freyer et al. for thin graphitic layers produced by ethylene decomposition on $\operatorname{Pt}(111)$ [45]. On polycrystalline platinum (Pt black) a C1s BE of $284.6 \mathrm{eV}$ was assigned to graphitic carbon whereas values of 284.1 and $284.4 \mathrm{eV}$ were attributed to lower-dimensional condensation products of "chain" carbon and graphene, respectively [46]. According to numerous previous experiments at the ISSIS beam line the $\mathrm{C} 3$ component at $284.75 \mathrm{eV}$ is assigned to more disordered $\mathrm{C}-\mathrm{C}$ bonding [44]. A similar C1s BE energy was found by Paàl on Pt and Pt-supported catalyst under ethylene atmosphere and interpreted there as hydrogenated carbon overlayer [47]. As shown by previous experiments at the ISISS beamline the $\mathrm{C} 1$ component at $283.6 \mathrm{eV}$ can be attributed to a carbidic species [44]. Rodriguez and co-workers attributed a C1s BE of $284.1 \mathrm{eV}$ to lower-dimensional condensation products of "chain" carbon representing a precursor phase of the graphitic overlayer [46]. Here, at lower temperature, at $650 \mathrm{~K}$, it is rather likely, that condensation to graphite is incomplete and some $\mathrm{CH}_{\mathrm{x}}$ species are still present. The region around $284 \mathrm{eV}$ might, for example, also contain an ethylidyne species because in an XPS study of $\mathrm{Pt}(111) / \mathrm{C}_{2} \mathrm{H}_{4}$ a C1s BE of $284 \mathrm{eV}$ was assigned to this species [48]. Gas phase ethylene is responsible for the $\mathrm{C} 4$ peak at $286.19 \mathrm{eV}$. 
No changes in the $\mathrm{BE}$ of the $\mathrm{C} 1 \mathrm{~s}$ components are observed during application of potential of $2 \mathrm{~V}$. From the decrease of the Pt4f signal by about $90 \%$ (see Fig. 6a), relative to the carbon free surface it is evident that carbonaceous $\mathrm{CH}_{\mathrm{x}}$ film has to be several layers thick. A rough estimate of the thickness can be made from the ratio of the $\mathrm{C} 1 \mathrm{~s}$ signal, $\mathrm{I}_{\mathrm{C}}$, to the $\mathrm{Pt} 4 \mathrm{f}$ signal of the substrate, $\mathrm{I}_{\mathrm{S}}$, (see experimental section) under the assumption that the Pt $4 \mathrm{f}$ signal is exponentially damped by a thick carbon film with thickness, $t$. Expressing $t$ in monolayers one obtains the plot in Fig. 5b.

As demonstrated by Fig. $5 \mathrm{~b}$ the maximum carbon coverage is reached at the rate maximum with an average thickness of the carbonaceous film of about 5-6 monolayers (ML). The film thickness undergoes some variations beyond the rate maximum and starts to decrease continuously beyond a ratio $\mathrm{p}\left(\mathrm{C}_{2} \mathrm{H}_{4}\right) / \mathrm{p}\left(\mathrm{O}_{2}\right)$ of 3 . Beyond a ratio of 10 the thickness increases again slightly but it has not been established whether this is a reproducible effect. At high $\mathrm{p}\left(\mathrm{C}_{2} \mathrm{H}_{4}\right)$ the data indicate a thickness of about $3 \mathrm{ML}$. Upon application of an electric potential we only observe a change in the carbon signal at low $\mathrm{p}\left(\mathrm{C}_{2} \mathrm{H}_{4}\right)$ i.e. before the rate maximum in the rate plot of Fig. 3a but not beyond the rate maximum with high $\mathrm{p}\left(\mathrm{C}_{2} \mathrm{H}_{4}\right)$ values as shown by Fig. 5. The $\mathrm{C} 1 \mathrm{~s}$ spectra reproduced in Fig. 7 illustrate a different behavior with respect to electrochemical pumping in different regions of the kinetics. With a large excess of oxygen electrochemical pumping causes a drastic decrease of the carbon signal by $\approx 67 \%$ at $\mathrm{p}\left(\mathrm{C}_{2} \mathrm{H}_{4}\right) / \mathrm{p}\left(\mathrm{O}_{2}\right)=1: 10$ and by $\approx 37 \%$ at $\mathrm{p}\left(\mathrm{C}_{2} \mathrm{H}_{4}\right) / \mathrm{p}\left(\mathrm{O}_{2}\right)=1: 5$. In contrast, practically no effect has been observed in case of large excess of ethylene i.e. at ratio $\mathrm{p}\left(\mathrm{C}_{2} \mathrm{H}_{4}\right) / \mathrm{p}\left(\mathrm{O}_{2}\right)=10: 1$ as shown in Fig. $7 \mathrm{~b}$.

The reduction in the carbon signal is accompanied by an increase in the oxygen coverage as demonstrated by Fig. 8a showing the O1s region under OC conditions and during electrochemical pumping. Already without applying a potential the O1s signal contains at least four species (O1-O4) as demonstrated by Fig. 8c which was recorded with an excess of ethylene $\left(\mathrm{p}\left(\mathrm{C}_{2} \mathrm{H}_{4}\right) / \mathrm{p}\left(\mathrm{O}_{2}\right)=5: 1\right)$. The main component $\mathrm{O} 3$ at $531.77 \mathrm{eV}$ is found typically on $\mathrm{Pt}$ catalysts under high pressure reaction conditions ( $p>10^{-3}$ mbar) [37]. It can be assigned to $\mathrm{SiO}_{\mathrm{x}}$ with $\mathrm{x}$ being close to two. The $\mathrm{SiO}_{2}$ is more or less inert but since $\mathrm{Si}$ accumulates this component reaches a substantial height in the course of a high pressure study. The silicon abundance goes up to $2 \%$ at maximum (Fig. S2 in Supporting Information). The O4 component at $533 \mathrm{eV}$ originates from various oxygen containing carbon compounds [49]. The component $\mathrm{O} 2$ at $530.4 \mathrm{eV}$ can be assigned to chemisorbed oxygen on Pt sites [7,38,50]. An additional oxygen component, $\mathrm{O} 1$, is seen at $529.3 \mathrm{eV}$, a BE characteristic for oxygen on $\operatorname{Ag}[20,51]$. 
Returning to spectrum in Fig. 8a we see that already prior to electrochemical pumping but with a large excess of oxygen $\left(\mathrm{p}\left(\mathrm{C}_{2} \mathrm{H}_{4}\right) / \mathrm{p}\left(\mathrm{O}_{2}\right)=1: 5\right)$, the dominant oxygen component is the one at $529.3 \mathrm{eV}$. Upon electrochemical pumping, it is this component which strongly grows by $\approx 60 \%$. A close-lying BE at $529.6 \mathrm{eV}$ has been found in an XPS study of $\mathrm{Ag} / \mathrm{YSZ}$ and identified there as electrochemically induced oxygen spillover species [20]. A spillover oxygen species on $\mathrm{Pt}$ which is identical with chemisorbed oxygen on Pt should appear at $530.4 \mathrm{eV}$ as demonstrated in a study with a microstructured Pt/YSZ sample where the identity of electrochemically induced oxygen spillover was verified with XPS [7]. This contribution is missing here or quite small. Assuming that alloying has not strongly shifted the BE's we assign the $529.3 \mathrm{eV}$ component to spillover oxygen on $\mathrm{Ag}$ sites. Evidently, we observe electrochemically induced oxygen spillover but we can only detect a spillover species over $\mathrm{Ag}$ sites and not over Pt sites. As indicated by Fig. 8a, growth of the $529.3 \mathrm{eV}$ component due to electrochemical pumping is only detectable at low $\mathrm{p}\left(\mathrm{C}_{2} \mathrm{H}_{4}\right)$, i. e. before the rate maximum in the rate curve of Fig. 3a. Beyond the rate maximum only slight changes in the O1s spectrum occur upon electrochemical pumping as shown in Fig. 8b.

The different adsorption states of oxygen on Ag have been studied quite in detail due to the importance of $\mathrm{Ag}$ as catalyst [51,52]. An oxygen state characterized by an $\mathrm{O} 1 \mathrm{~s} \mathrm{BE}$ of $529.3 \mathrm{eV}$ was found here for the spillover species onto Ag sites. This value is not far from the $\mathrm{BE}$ of $529.6 \mathrm{eV}$ reported for the $\gamma$-species on $\mathrm{Ag}$ but it is more closely to the $\mathrm{O}_{2 \alpha}$ state reported recently with an $\mathrm{O} 1 \mathrm{~s} \mathrm{BE}$ of $529.2 \mathrm{eV}$ [52]. Therefore instead of assigning the spillover species to the highly stable $\gamma$-species formed on $\mathrm{Ag}$ in high temperature/high pressure ( 1 bar) $\mathrm{O}_{2}$ treatments the peak is assigned to the $\mathrm{O}_{2 \alpha}$ state which develops on $\mathrm{Ag}$ foil and on $\operatorname{Ag}(110)$ already under milder conditions, i. e., at 0.25 mbar and with temperatures between $150{ }^{\circ} \mathrm{C}$ and $230{ }^{\circ} \mathrm{C}$ [52]. The presence of the $\mathrm{O}_{2 \alpha}$ state was found to be correlated with as shift of the Ag3d BE of $0.5 \mathrm{eV}$ but in the EPOC experiments no such shift was found. The reason for this might be that the Ag3d already experienced a downward shift of $0.59 \mathrm{eV}$ due to alloying with $\mathrm{Pt}$ (s. section 3.1). Also in the Ag/YSZ study of Zipprich et al. the formation of the $529.6 \mathrm{eV}$ oxygen spillover species upon electrochemical pumping was not correlated with any change in the Ag3d peak position [20]. Since this does not agree with findings for $\mathrm{O}_{2 \alpha}$ state the exact nature of the oxygen spillpover species on $\mathrm{Ag} / \mathrm{YSZ}$ still needs to be clarified.

The variation of the Pt/Ag ratio during the EPOC experiments is depicted in Fig. 9. Beyond the rate maximum with an excess of ethylene the $\mathrm{Pt} / \mathrm{Ag}$ ratio is around 1.5-1.7. 
Application of an electric potential in this region does not lead to significant changes in the $\mathrm{Pt} / \mathrm{Ag}$ ratio in this region. However, left of the rate maximum in the first two data points $\mathrm{Pt}$ is enriched compared to the range where ethylene is in excess. Upon electrochemical pumping the enrichment of $\mathrm{Pt}$ is enhanced. The $\mathrm{Pt} / \mathrm{Ag}$ ratio is equal 3.25 and 2.6 for $\mathrm{C}_{2} \mathrm{H}_{4} / \mathrm{O}_{2}$ ratios of 1:10 and 1:5, respectively; upon electrochemical pumping the $\mathrm{Pt} / \mathrm{Ag}$ ratio increases to 4.25 and 3.2 (see Fig. 9b). The region where the $\mathrm{Pt} / \mathrm{Ag}$ ratio changes is also the region where electrochemical pumping causes a strong reduction of the carbon signal and a substantial increase in oxygen coverage. A potential explanation for the Pt enrichment might therefore be that electrochemical pumping preferentially removes carbon from Pt sites (Fig. 6 and Fig S4). An alternative possibility is that the increase in oxygen coverage causes Pt to segregate to the surface. This possibility can be discarded because the O1s spectra indicate that the spillover oxygen binds to Ag and not to Pt sites.

\subsection{Kinetic instabilities}

At ratios $\mathrm{p}\left(\mathrm{C}_{2} \mathrm{H}_{4}\right) / \mathrm{p}\left(\mathrm{O}_{2}\right)$ larger than 10:1 kinetic instabilities occur and kinetic oscillations may develop as demonstrated by Fig. 10. Under OC conditions rate oscillations may evolve spontaneously as shown in Fig. 10a for a ratio $\mathrm{p}\left(\mathrm{C}_{2} \mathrm{H}_{4}\right) / \mathrm{p}\left(\mathrm{O}_{2}\right)=12.5: 1$. They are irregular in amplitude and period with an average period around $20 \mathrm{~s}$. From a noisy background sharp outbursts of the $\mathrm{CO}_{2}$ signal occur after which the rate returns to the baseline. Applying an electric potential $\mathrm{V}_{\mathrm{WR}}=2 \mathrm{~V}$ causes the rate oscillations to vanish. After removing the applied voltage and establishing $\mathrm{OC}$ conditions the $\mathrm{CO}_{2}$ rate returns to the original level and the rate oscillations reappear but now much more regular approaching harmonic oscillations with an average period around $10 \mathrm{~s}$. At even larger $\mathrm{p}\left(\mathrm{C}_{2} \mathrm{H}_{4}\right) / \mathrm{p}\left(\mathrm{O}_{2}\right)$ ratios a sequence complementary to the one depicted in Fig. 10a can be observed. As demonstrated by Fig. $10 \mathrm{~b}$ for a ratio $\mathrm{p}\left(\mathrm{C}_{2} \mathrm{H}_{4}\right) / \mathrm{p}\left(\mathrm{O}_{2}\right)=15: 1$ the rate is stationary under OC conditions but upon electrochemical pumping rate oscillations develop. The rate oscillations have been followed over a period of nearly two hours but during this time the character of the oscillations changes. While initially the rate jumps in an irregular way between an upper and a lower rate level, after $6300 \mathrm{~s}$ the rate remains mostly on the upper level with occasional spikelike excursions to the lower rate level. After reestablishing OC conditions the rate returns to the initial stationary level.

\section{Discussion}


For explaining the EPOC effect in the $\mathrm{C}_{2} \mathrm{H}_{4}+\mathrm{O}_{2}$ reaction on $\mathrm{Pt} / \mathrm{YSZ}$ the following mechanistic scheme based on ignition has been proposed $[11,12]$. The EPOC effect occurs only under conditions of ethylene excess so that a carbonaceous layer on Pt can build up which inhibits $\mathrm{O}_{2}$ adsorption and hence poisons the catalyst. The effect of the electric potential is to generate oxygen spillover which eats holes into the carbon layer thus removing locally the inhibitory effect. Now $\mathrm{O}_{2}$ adsorption from the gas phase can occur enlarging these holes via reaction fronts. Through partial removal of the carbonaceous layer the fronts initiate the transition from an unreactive to a reactive state of the surface. In this picture the role of spillover oxygen is just to ignite the reaction and consequently the EPOC effect is nonFaradaic.

With regard to the kinetics of the reaction (Fig. 3a) and the conditions for EPOC the picture for ethylene oxidation over $\mathrm{Pt}-\mathrm{Ag} / \mathrm{YSZ}$ is very much the same as for ethylene oxidation over Pt/YSZ. A closer look at the results of the in situ XPS measurements reveals, however, a number of observations which, at least at first sight, seems not to agree at all with the mechanism sketched above:

(i) In contrast to pure Pt electrodes we already find a substantial carbon coverage at low $\mathrm{p}\left(\mathrm{C}_{2} \mathrm{H}_{4}\right)$ before the rate maximum is reached. Electrochemical pumping decreases the carbon signal but in contrast to what one expects, the partial removal of the carbonaceous layer has no effect on the rate.

(ii) At high $\mathrm{p}\left(\mathrm{C}_{2} \mathrm{H}_{4}\right)$ an EPOC effect is seen but again in contrast to what one expects the rate increase is not accompanied by a decrease of the carbon signal.

We can resolve the apparent contradictions between the observations in (i) and the proposed mechanism if we take into account that $\mathrm{Ag}$ is less reactive in the total oxidation of ethylene than Pt. If the Pt in the Pt-Ag/YSZ system behaves similar to Pt/YSZ, then the Pt should be carbon free at low $\mathrm{p}\left(\mathrm{C}_{2} \mathrm{H}_{4}\right)$, and all the carbon should be concentrated on $\mathrm{Ag}$ sites. Since the Pt sites are the active sites, it is evident that a decrease of the carbon coverage on the $\mathrm{Ag}$ sites will have no consequences for the reaction rate. This mechanistic picture is schematically depicted in Fig. 11.

An alternative possibility would be that part of the carbonaceous layer becomes graphitic and thus electrically conducting [53,54]. This graphitic carbon if it grows at the tpb could therefore also act as an electrode thus potentially enforcing the electrochemical promotion effect. Since this hypothesis found no experimental support it is pursued any further here. 
The fact that upon electrochemical pumping we see only strong growth of oxygen on $\mathrm{Ag}$ sites but not of oxygen on Pt sites does not mean that we have no oxygen spillover on Pt. What we measure is the stationary oxygen concentration. Therefore, if the spillover oxygen on $\mathrm{Pt}$ is much more reactive than spillover oxygen on $\mathrm{Ag}$, we will consequently observe a high concentration of oxygen on Ag sites and a low concentration on Pt sites under reaction conditions. The different reactivities of the oxygen spillover species over Pt and Ag sites explains the $\mathrm{O} 1 \mathrm{~s}$ spectra made left of the rate maximum. At high $\mathrm{p}\left(\mathrm{C}_{2} \mathrm{H}_{4}\right)$ electrochemical pumping does not lead to a detectable growth in oxygen coverage but again this probably just reflects the fact that with a large excess of ethylene the stationary concentration in reactive oxygen species will be very small.

The observation that the EPOC effect at high $\mathrm{p}\left(\mathrm{C}_{2} \mathrm{H}_{4}\right)$ is not connected with a decrease of the carbon signal is in apparent contradiction to the mechanistic picture established for Pt/YSZ of a reaction front spreading out reactively removing carbon. The only valid conclusion from the experimental data can be that in our case there is no reaction front, but then the question is why no front develops? If we get back to the mechanistic picture of how a reaction front develops, then this is via spillover oxygen eating a hole into a carbon adlayer followed by oxygen adsorbing from the gas phase and reacting thus enlarging the hole. This mechanism works well if the carbonaceous film is not more than 1 ML thick but in our case the film is $\approx 5-6 \mathrm{ML}$ thick. Initiating a front under isothermal conditions will be quite difficult then.

A "non-Faradaic efficiency factor", $\Lambda$, has been defined which according to the stoichiometry of ethylene combustion is obtained as $\Lambda=\Delta \mathrm{r} /(\mathrm{I} / 6 \mathrm{~F})$ with $\Delta \mathrm{r}$ denoting the rate increase in $\mathrm{CO}_{2}$ production and I representing the electric current flow between counter and working electrode $[3,4]$. Here for an ionic current $\mathrm{I}=5 \mathrm{~mA}$ and with an effective pumping rate of $0.44 \mathrm{~L} / \mathrm{s}$ one calculates from the measured QMS signal a $\Lambda$-factor of 2.18. The electrochemical promotion effect is therefore weakly non-Faradaic.

A Faradaic rate increase, i. e. $\Lambda=1$, means that the electrochemically induced rate increase is entirely caused by spillover oxygen which reacts with the decomposition products of ethylene adsorption whereas gas phase oxygen plays no role. A value $\Lambda \approx 2$ indicates that both, oxygen from the gas phase and spillover oxygen, contribute about equally strong to the reaction rate. If, in a first approximation we neglect the gas phase contribution the following picture of the EPOC process results. The three-phase-boundary is surrounded by a reaction zone whose spatial extension, $r$, is given by the diffusivity $D_{O}$ of spillover oxygen and the 
lifetime $\tau$ of spillover oxygen according to $r=\sqrt{ } 2 D_{0} \tau$. The lifetime of spillover oxygen is given by the impingement rate of ethylene multiplied with the reactive sticking coefficient; assuming $\mathrm{S}_{\text {reac }}=0.1$ about $10^{4}$ monolayers adsorb per second resulting in a lifetime of the order of $10^{-4} \mathrm{~s}$ for spillover oxygen. With an oxygen diffusivity $D_{O}=1.24 \times 10^{-5} \mathrm{~cm}^{2} \mathrm{~s}^{-1}$ for $650 \mathrm{~K}$ one obtains a width of the reaction zone of $0.5 \mu \mathrm{m}$ [55]. Apparently the reaction zone is so small that it does not lead to a detectable change in the carbon signal. This reaction zone is located around the tpb but since we are using porous Pt electrodes this means that the tpb and therefore the reaction zone are not accessible to direct observation with XPS. Of course, in numerous experiments with porous Pt electrodes on YSZ spillover oxygen was measured. This means that the spillover oxygen originating at the tpb must have a sufficient mobility to reach the outer surface of the electrodes to be detected by surface analytical techniques such as XPS, PEEM or work function measurements with a Kelvin probe [2,4,7,8]. This requires a diffusion length of the order of micrometers and such conditions are given if the experiments are not conducted in a reacting environment. Under our conditions with a reaction limiting the life time of spillover oxygen the diffusion length is not sufficient to reach the outer surface of the electrode.

As one compares the EPOC effect found here with data in the literature for ethylene oxidation over Pt/YSZ one finds a quite different behavior. The highest $\Lambda$-factor of all EPOC systems investigated so far is reported with $\Lambda=3 \times 10^{5}$ for ethylene oxidation over Pt/YSZ [18]. This investigation was carried out with reactants in the $10^{-2}$ mbar range and with helium as carrier gas at $\approx 1$ bar. In a PEEM study of ethylene oxidation over Pt/YSZ conducted at $10^{4}$ mbar a $\Lambda$-factor of 2.4 was obtained [11,12]. In the case of the atmospheric pressure study one can suspect that the huge $\Lambda$-factor is the result of thermal ignition as the reaction becomes non-isothermal.

One main motivation for this study has been the possibility that at high pressure an oxygen spillover species might develop which is different from chemisorbed oxygen. The existence of such a special spillover species has been postulated by Vayenas and co-workers in order to explain the non-Faradaic nature of the EPOC effect but so far no valid experimental proof exists [4,5,9]. Also here no indication for the existence of $\mathrm{O}^{\delta-}$ species with $\delta$ close to 2 was found. According to the XPS study by Ladas et al. the O $1 \mathrm{~s}$ BE of this species should be located at $528.8 \mathrm{eV}$ [10]. Following the "sacrificial promoter" concept of Vayenas this species should exhibit a reduced reactivity compared to regular chemisorbed oxygen. 
Therefore even in a reacting environment this species should reach a substantial concentration but no new component was found in the experimental data.

One could be tempted to summarize the results by stating that on the alloyed surface the two metallic constituents retain their individual behavior in the electrochemical promotion experiments. This would be problematic for several reasons. First of all, the XPS data alone do not allow us to directly separate the electrocatalytic contributions of the two metallic constituents. Nevertheless we could deduce a model from the measurements which consistently explained the available data. Following this model the Pt on the alloyed surface behaves like pure Pt electrodes in EPOC experiments conducted under the same conditions [56]. For Ag the case is more difficult. Firstly, no in situ XPS data are available for the EPOC behavior of Ag/YSZ at high pressure. Secondly, the shift of the Ag3d BE indicates alloying with Pt. Since we observe the formation of a several monolayers thick carbon layer on the $\mathrm{Pt} / \mathrm{Ag}$ catalyst while on pure $\mathrm{Pt}$, under the same conditions, the thickness of the carbon layer does not exceed one monolayer the effect of the Ag is evident. Whether this effect is due to alloying or whether this would also be observed on pure Ag is a question which remains to be solved in the future.

Kinetic oscillations occur in certain parameter range for a quite large number of heterogeneously catalyzed reactions comprising a pressure range from $10^{-9}$ mbar to atmospheric pressure [57]. In ethylene oxidation over $\mathrm{Pt}$ and $\mathrm{Rh}$ rate oscillations have been found in experiments conducted in the mbar - 1 bar range [58]. In EPOC experiments rate oscillations have been observed under galvanostatic control in catalytic $\mathrm{CO}$ oxidation over $\mathrm{Pt} / \mathrm{YSZ}$ and in ethylene oxidation over Rh/YSZ [59-61]. Since the oscillations in catalytic CO oxidation occurred at the borderline of the stability range of Pt oxide a mechanism based on the periodic formation and reduction of Pt oxide has been suspected. In principle, numerous feedback mechanisms can potentially cause kinetic instabilities; without further experimental evidence, it is therefore of little use to speculate about possible oscillation mechanisms [57].

\section{Conclusions}

The experiments presented here are the first EPOC experiments at high pressure (close to 1 mbar) in which the state of the surface was monitored in situ using XPS to identify the relevant surface species. An electrochemical promotion of ethylene oxidation over bimetallic Pt-Ag/YSZ catalysts has been found. The promotion effect is weakly non-Faradaic, i. e. spillover oxygen and oxygen from the gas phase contribute about equally strong to the 
reaction rate. As found for ethylene oxidation over Pt/YSZ the promotion effect is linked to the presence of a carbonaceous $\mathrm{CH}_{\mathrm{x}}$ layer inhibiting $\mathrm{O}_{2}$ adsorption and hence poisoning the catalytic surface. An EPOC effect accordingly is only observed at high $\mathrm{p}\left(\mathrm{C}_{2} \mathrm{H}_{4}\right) / \mathrm{p}\left(\mathrm{O}_{2}\right)$ ratios. Under conditions under which we see an electrochemical promotion no effect of the pumping voltage on the carbon signal and on the oxygen signal can be detected. The absence of such an effect is attributed (i) to a rather thick carbonaceous film which comprises about 5-6 ML and (ii) due to a relatively small reaction zone around the tpb. In contrast, at low $\mathrm{p}\left(\mathrm{C}_{2} \mathrm{H}_{4}\right)$ under conditions where no EPOC effect occurs electrochemical pumping leads to the appearance of an oxygen spillover species at $529.3 \mathrm{eV}$ simultaneous with a decrease of the carbon signal. The spillover oxygen is assigned to oxygen on Ag sites which is less reactive than oxygen spillover over Pt sites species and therefore can be detected. An effect which has to be attributed to $\mathrm{Ag}$ is the formation of a several layers thick $\mathrm{CH}_{\mathrm{x}}$ film. Under no conditions we observed any indication of a special spillover oxygen species $\left(\mathrm{O}^{\delta-}\right.$ with $\delta$ around 2$)$ which has been postulated for Pt/YSZ [3-5].

Acknowledgments. Financial support from the Deutsche Forschungsgemeinschaft (DFG) is gratefully acknowledged. 


\section{References}

[1] C. Wagner, Adv. Catal. 21 (1970) 32.

[2] C.G. Vayenas, S. Bebelis, S. Ladas, Nature 343 (1990) 625.

[3] C.G. Vayenas, M.M. Jaksic, S.I. Bebelis, S.G. Nephytides, in: J.O.M. Bockris et al. (Eds.), Modern Aspects of Electrochemistry, 29, Plenum Press, New York, 1996, p. 57.

[4] C. G. Vayenas, S. Bebelis, C. Pliangos, S. Brosda, D. Tsiplakides, Electrochemical Activation of Catalysis: Promotion, Electrochemical Promotion, and Metal-Support Interactions, Kluwer Academic / Plenum Publishers, New York, 2001.

[5] R. Imbihl, Prog. Surf. Sci. 85 (2010) 240.

[6] R. J. Gorte, J. M. Vohs, Annu. Rev. Biomol. Eng. 2 (2011) 9; C. Zhang, M. E. Grass, A. H. McDaniel, S. C. DeCaluwe, F. El Gabaly, Z. Liu, K. F. McCarty, R. L. Farrow, M. A. Linne, Z. Hussain, G. S. Jackson, H. Bluhm, B. W. Eichhorn, Nat. Mater. 9 (2010) 944.

[7] B. Luerßen, S. Günther, H. Marbach, M. Kiskinova, J. Janek, R. Imbihl, Chem. Phys. Lett. 316 (2000) 331.

[8] B. Luerßen, E. Mutoro, H. Fischer, S. Günther, R. Imbihl, J. Janek, Angew. Chem. Int. Ed. 45 (2006) 1473.

[9] C. G. Vayenas, P. Vernoux, ChemPhysChem 12 (2011) 1761; R. Imbihl, A. Toghan, ChemPhysChem 12 (2011) 1764.

[10] S. Ladas, S. Kennou, S. Bebelis, C. G. Vayenas, J. Phys. Chem. 97 (1993) 8845.

[11] A. Toghan, L. M. Rösken, R. Imbihl, ChemPhysChem 11 (2010) 1452.

[12] A. Toghan, L. M. Rösken, R. Imbihl, Phys. Chem. Chem. Phys. 12 (2010) 9811.

[13] V.A. Sobyanin, V.D. Belyaev, React. Kinet. Catal. Lett. 51 (1993) 373.

[14] V.D. Belyaev, T.I. Politova, V.A. Sobyanin, Catal. Lett. 57 (1999) 43.

[15] V. D. Belyaev, T. I. Politova, V. A. Sobyanin, Sol. State Ion. 136-137 (2000) 721.

[16] I. V. Yentekakis, A. Palermo, N. C. Filkin, M. S. Tikhov, R. M. Lambert, J. Phys. Chem. B 101 (1997) 3759.

[17] E. Mutoro, B. Luerssen, S. Guenther, J. Janek, Solid State Ion. 180 (2009)1019. 
[18] S. Bebelis, C. G. Vayenas, J. Catal. 118 (1989) 125.

[19] E. Mutororo, C. Koutsodontis, B. Luerssen, S. Brosda, C.G. Vayenas, J. Janek, Appl. Catal., B 100 (2010) 328.

[20] W. Zipprich, H. D. Wiemhöfer, U. Vöhrer, W. Göpel, Ber. Bunsen.-Ges. Phys. Chem. 99 (1995) 1406.

[21] J. Sanabria-Chinchilla, K. Asazawa, T. Sakamoto, K. Yamada, H. Tanaka, P. Strasser, J. Am. Chem. Soc. 133 (2011) 5425.

[22] A. Toghan, M. Khodari, F. Steinbach, R. Imbihl, Thin Solid Films 519 (2011) 8139.

[23] J. Winkler, P. V. Hendriksen, N. Bonanos, M. Mogensen, J. Electrochem. Soc. 145 (1998) 1184.

[24] D. F Ogletree, H. Bluhm, G. Lebedev, C. S. Fadley, Z. Hussain, M. Salmeron, Rev. Sci. Instrum. 73 (2002) 3872.

[25] A. Knop-Gericke, E. Kleimenov, M. Hävecker, R. Blume, D. Teschner, S. Zafeiratos, R. Schlögl, V. I. Bukhtiyarov, V. V. Kaichev, I. P. Prosvirin, A. I. Nizovskii, H. Bluhm, A. Barinov, P. Dudin, M. Kiskinova, Adv. Catal. 52 (2009) 213.

[26] The IMFP of electrons at $150 \mathrm{eV}$ were calculated using Quases-Tougard TPP2M software.

[27] D. A. Shirley, Phys. Rev. B 5 (1972) 4709.

[28] N. Fairley, A. Carrick, The Casa Cookbook - Part 1: Recipes for XPS Data Processing, Acolyte Science, Kinderton Close, High Legh, Knutsford, Cheshire, WA16 6LZ U.K., 2005.

[29] J. J. Yeh, I. Lindau, Atom. Data Nucl. Data Tables 32 (1985) 1.

[30] J. E. Fulghum, R. W. Linton, Surf. Interface Anal. 13 (1988) 186.

[31] M. Eizenberg, M. Blekely, Surf. Sci. 82 (1979) 228.

[32] D. Poulidi, M. E. Rivas, I. S. Metcalfe, J. Catal. 281 (2011) 188.

[33] F. Bensebaa, N. Patrito, Y. Le Page, P. L'Ecuyer, D.Wang, J. Mater. Chem. 14 (2004) 3378 .

[34] A. S. Arico`, P. Creti, H. Kim, R. Mantegna, N. Giordano,V. Antonucci, J. Electrochem. Soc. 143 (1996) 3950. 
[35] Q. Li, K. Wang, S. Zhang, M. Zhang, J. Yang, Z. Jin, J. Mol. Catal. A: Chem. 258 (2006) 83.

[36] A.M. Ruppert, T. Paryjczak, Appl. Catal., A 320 (2007) 80.

[37] S. Günther, A.Scheibe, H. Bluhm, M. Haevecker, E. Kleimenov, A. Knop-Gericke, R. Schlögl, and R. Imbihl, J. Phys. Chem. C 112 (2008) 15382.

[38] C.R. Parkinson, M. Walker, C.F. McConville, Surf. Sci. 545 (2003) 19.

[39] J. B. Xu, T. S. Zhao, Z. X. Liang, J. Phys. Chem. C 112 (2008) 17362.

[40] D. Zhao, Y-H. Wang, B. Yan, B-Q. Xu, J. Phys. Chem. C 113 (2009) 1242.

[41] C. G. Freyschlag, R. J. Madix, Mater. Today, 14 (2011) 134.

[42] C. Koutsodontisa, A. Katsaounisa, J.C. Figueroab, C. Cavalcab, Carmo. J. Pereirab, C.G. Vayenas, Top. Catal. 38 (2006) 157.

[43] R. Larciprete, S.Lizzit, S. Botti, C. Cepek, A. Goldoni, Phys. Rev. B 66 (2002) 121402.

[44] S. Hofmann, R. Blume, C. T. Wirth, M. Cantoro, R. Sharma, C. Ducati, M. Hävecker, S. Zafeiratos, P. Schnoerch,, A. Oestereich, D. Teschner, M. Albrecht, A. Knop-Gericke, R. Schlögl, J. Robertson, J. Phys. Chem. C 113 (2009) 1648.

[45] N. Freyer, G. Pirug, H. P. Bonzel, Surf. Sci. 126 (1983) 487.

[46] N. M. Rodriguez, P. E. Anderson, A. Wootsch, U. Wild, R. Schlögl, Z. Paàl, J. Catal. 197 (2001) 365.

[47] Z. Paàl, J. Mol. Catal. 94 (1994) 225.

[48] T. Fuhrmann, M. Kinne, B. Tränkenschuh, C. Papp, J. F. Zhu, R. Denecke, H-P. Steinrück., New J. Phys. 7 (2005) 107.

[49] B. A. Sexton, A. E. Hughes, Surf. Sci. 140 (1984) 227.

[50] C. Puglia, A. Nilsson, B. Hernnas, O. Karis, P. Bennich, N. Martensson, Surf. Sci. 342 (1995) 119.

[51] V. I. Bukhtiyarov, A. Nizovskii, H. Bluhm, M. Hävecker, E. Kleimenov, A. KnopGericke, R. Schlögl, J. Catal. 238 (2006) 260. 
[52] T. C. R. Rocha, A. Oestereich, D. V. Demidov, M. Hävecker, S. Zafeiratos, G. Weinberg, V. I. Bukhtiyarov, A. Knop-Gericke, R. Schlögl, Phys. Chem. Chem. Phys. 14 (2012) 4554.

[53] S. Park, J. M. Vohs, R. J. Gorte, Nature 404 (2000) 265.

[54] S. McIntosh, J. M. Vohs, R. J. Gorte, J. Electroch. Soc. 150 (2003) A470.

[55] E. Mutoro, C. Hellwig, B. Luerssen, S. Guenther, W. Bessler, J. Janek, Phys. Chem. Chem. Phys. 13 (2011) 12798.

[56] A. Toghan, M. Greiner, R. Arrigo, A. Knop-Gericke, R. Imbihl, in preparation.

[57] R. Imbihl, G. Ertl, Chem. Rev. 95 (1995) 697.

[58] C. G. Vayenas, C. Georakis, J. Michaels, J. Tormo, A. Ioannides, S. Bebelis, J. Catal. 67 (1981) 348.

[59] I. V. Yentekakis, C. G. Vayenas, J. Catal. 111 (1988) 170.

[60] M. N. Tsampas, F. M. Sapoutzki, C. G. Vayenas, Catal. Today 146 (2009) 351.

[61] E.A. Baranova, A. Thursfield, S. Brosda, G. Fo' ti, C. Comninellis, C.G. Vayenas, Catal. Lett. 150 (2005) 15. 


\section{Figure Captions}

Fig. 1: (a) Schematic experimental set-up. (b) The actual dimensions of the sample and of the electrodes. $\mathrm{YSZ}=$ yttrium stabilized zirconia, $\mathrm{WE}=$ working electrode, $\mathrm{CE}=$ counter electrode, $\mathrm{RE}=$ reference electrode.

Fig. 2: Photoelectron spectra characterizing the bimetallic $\mathrm{Pt} / \mathrm{Ag}$ catalyst under reaction conditions. Experimental conditions: $\mathrm{p}\left(\mathrm{C}_{2} \mathrm{H}_{4}\right) / \mathrm{p}\left(\mathrm{O}_{2}\right)=10: 1, \mathrm{~T}=650 \mathrm{~K}, \mathrm{p}($ total $)=$ 0.25 mbar.

(a) Pt4f spectrum. The different components for spectral fitting have the positions: $\mathrm{P} 1=70.90 \mathrm{eV}, \mathrm{P} 2=71.84 \mathrm{eV}, \mathrm{P} 3=74.20 \mathrm{eV}$ and $\mathrm{P} 4=75.13 \mathrm{eV}$.

(b) Ag3d spectrum. Comparison of the spectra under OC conditions and with applied electric potential of $2 \mathrm{~V}$

Fig. 3: Kinetics of ethylene oxidation and electrochemical activation. Experimental conditions: $\mathrm{T}=650 \mathrm{~K}, \mathrm{p}($ total $)=0.25$ mbar.

(a) Rate vs. $\mathrm{p}\left(\mathrm{C}_{2} \mathrm{H}_{4}\right) / \mathrm{p}\left(\mathrm{O}_{2}\right)$ for OC conditions and with an applied electric potential $\mathrm{V}_{\mathrm{WR}}=2 \mathrm{~V}$. The noise level in the rate measurements was below $0.2 \%$ of the $\mathrm{CO}_{2}$ signal. The ionic current, $\mathrm{I}_{\mathrm{WC}}$, is $5 \mathrm{~mA}$ in the rate measurements to the right of the rate maximum; left of the rate maximum, under oxygen rich conditions, the current is up to a factor of 4 higher.

(b) The plot represents an enlarged section of Fig. 3a showing the behavior of the rate from zero up to the rate maximum under OC conditions and with an applied electric potential of $2 \mathrm{~V}$.

Fig. 4: Effect of electrochemical activation on the kinetics: Experimental conditions: $\mathrm{T}=650 \mathrm{~K}, \mathrm{p}($ total $)=0.25 \mathrm{mbar}$.

(a) Relative electrochemically induced rate increase vs. $\mathrm{p}\left(\mathrm{C}_{2} \mathrm{H}_{4}\right) / \mathrm{p}\left(\mathrm{O}_{2}\right)$. The data points are taken from Fig. 3.

(b) Effect of variation of applied electric potential at ratio $\mathrm{p}\left(\mathrm{C}_{2} \mathrm{H}_{4}\right) / \mathrm{p}\left(\mathrm{O}_{2}\right)=10: 1$.

Fig. 5: Variation of the carbon concentration during EPOC experiments. Experimental conditions: $\mathrm{T}=650 \mathrm{~K}, \mathrm{p}($ total $)=0.25 \mathrm{mbar}$.

(a) Carbon signal $\mathrm{C} 1 \mathrm{~s}$ vs. $\mathrm{p}\left(\mathrm{C}_{2} \mathrm{H}_{4}\right) / \mathrm{p}\left(\mathrm{O}_{2}\right)$ for $\mathrm{OC}$ conditions and with an applied electric potential of $2 \mathrm{~V}$. The thin dotted lines represent the rate curves from Fig. 3. The roman numbers indicate the sequence in which the data points were taken. 
(b) Variation of the thickness of the carbonaceous layer vs $\mathrm{p}\left(\mathrm{C}_{2} \mathrm{H}_{4}\right) / \mathrm{p}\left(\mathrm{O}_{2}\right)$ for OC conditions and with an applied electric potential of $2 \mathrm{~V}$ during EPOC experiments.

Fig. 6. Variation of the $\mathrm{C} / \mathrm{Pt}$ and the $\mathrm{C} / \mathrm{Ag}$ ratio during the EPOC experiment displayed in Fig. 3.

Fig 7. C1s photoelectron spectra showing the effect of electrochemical pumping. The spectra were all recorded under reaction conditions at $\mathrm{T}=650 \mathrm{~K}$ and $\mathrm{p}($ total $)=0.25$ mbar.

(a) Spectrum under OC conditions for $\mathrm{p}\left(\mathrm{C}_{2} \mathrm{H}_{4}\right) / \mathrm{p}\left(\mathrm{O}_{2}\right)=10: 1$ with the different contributions C1-4 indicated (see section 3.3).

(b) Comparison of the spectra under OC conditions and with applied electric potential of $2 \mathrm{~V}$ for a ratio $\mathrm{p}\left(\mathrm{C}_{2} \mathrm{H}_{4}\right) / \mathrm{p}\left(\mathrm{O}_{2}\right)=10: 1$.

(c-d) Same as in (a-b) but with oxygen being in excess, i. e. $p\left(\mathrm{C}_{2} \mathrm{H}_{4}\right) / \mathrm{p}\left(\mathrm{O}_{2}\right)=1: 10$.

(e) Effect of electrochemical pumping for $\mathrm{p}\left(\mathrm{C}_{2} \mathrm{H}_{4}\right) / \mathrm{p}\left(\mathrm{O}_{2}\right)=1: 5$.

Fig. 8: O 1s spectra showing the variation of the oxygen coverage during EPOC experiments. Experimental conditions: $\mathrm{T}=650 \mathrm{~K}, \mathrm{p}($ total $)=0.25 \mathrm{mbar}$.

(a) Formation of an oxygen spillover species under reaction conditions with oxygen in excess, i. e. $\mathrm{p}\left(\mathrm{C}_{2} \mathrm{H}_{4}\right) / \mathrm{p}\left(\mathrm{O}_{2}\right)=1: 5$. Shown is the $\mathrm{O} 1 \mathrm{~s}$ region for OC conditions and with an applied electric potential $\mathrm{V}_{\mathrm{WR}}=2 \mathrm{~V}$.

(b) Effect of electrochemical pumping under reaction conditions with ethylene in excess, i. e. $\mathrm{p}\left(\mathrm{C}_{2} \mathrm{H}_{4}\right) / \mathrm{p}\left(\mathrm{O}_{2}\right)=5: 1$.

(c) Decomposition of the O1s spectrum under reaction conditions with ethylene in excess, i. e. $\mathrm{p}\left(\mathrm{C}_{2} \mathrm{H}_{4}\right) / \mathrm{p}\left(\mathrm{O}_{2}\right)=5: 1$ into components O1-4 (see section 3.3).

Fig. 9: Variation of the $\mathrm{Pt} / \mathrm{Ag}$ ratio during EPOC experiments. Experimental conditions: $\mathrm{T}=650 \mathrm{~K}, \mathrm{p}($ total $)=0.25$ mbar.

(a) $\mathrm{Pt} / \mathrm{Ag}$ ratio vs. $\mathrm{p}\left(\mathrm{C}_{2} \mathrm{H}_{4}\right) / \mathrm{p}\left(\mathrm{O}_{2}\right)$ for $\mathrm{OC}$ conditions and with an applied electric potential of $2 \mathrm{~V}$.

(b) The drawing represents an enlarged section of Fig. 9a showing the effect of an applied electric potential on the first few data points.

Fig.10: Kinetic oscillations in an EPOC experiment. Experimental conditions: $\mathrm{T}=650 \mathrm{~K}$, $\mathrm{p}($ total $)=0.25$ mbar. 
(a) Development of rate oscillations under OC conditions and suppression of the rate oscillations by an applied electric potential at ratio $\mathrm{p}\left(\mathrm{C}_{2} \mathrm{H}_{4}\right) / \mathrm{p}\left(\mathrm{O}_{2}\right)=12.5: 1$.

(b) Stationary reaction kinetics under OC conditions and appearance of rate oscillations during electrochemical pumping at ratio $\mathrm{p}\left(\mathrm{C}_{2} \mathrm{H}_{4}\right) / \mathrm{p}\left(\mathrm{O}_{2}\right)=15: 1$.

Fig. 11: Scheme of the proposed electrochemical promotion mechanism of ethylene oxidation on bimetallic $\mathrm{Pt} / \mathrm{Ag}$ electrodes on YSZ. It is assumed that the spillover oxygen over $\mathrm{Pt}$ is far more reactive than over $\mathrm{Ag}$ sites.

(a) Promotion under conditions of oxygen being in excess, i. e. left of the rate maximum in reaction rate vs. $\mathrm{p}\left(\mathrm{C}_{2} \mathrm{H}_{4}\right) / \mathrm{p}\left(\mathrm{O}_{2}\right)$ plot (Fig. 3a).

(b) Promotion under conditions of ethylene being in excess, i. e. right of the rate maximum in reaction rate vs. $\mathrm{p}\left(\mathrm{C}_{2} \mathrm{H}_{4}\right) / \mathrm{p}\left(\mathrm{O}_{2}\right)$ plot (Fig. 3a). 
(a)

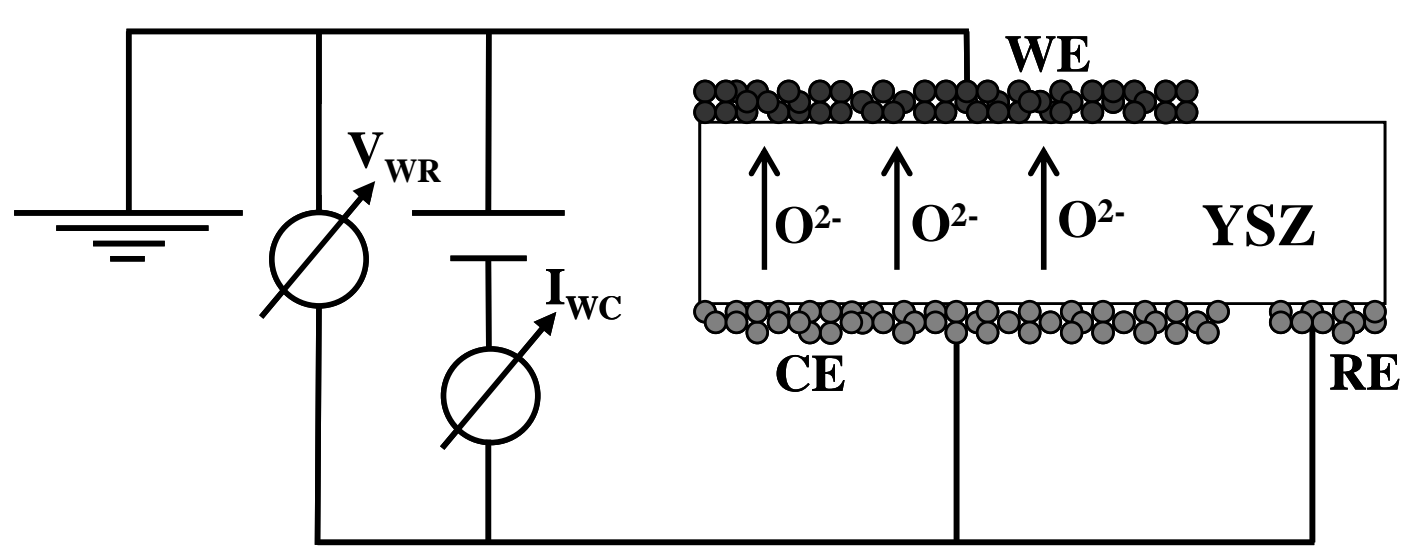

(b)

$16 \mathrm{~mm}$

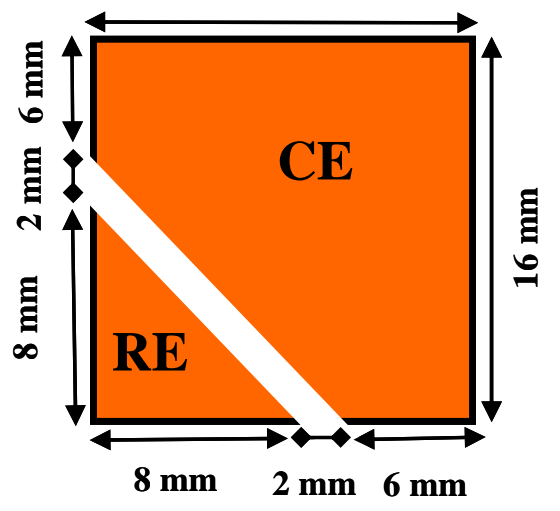

$16 \mathrm{~mm}$

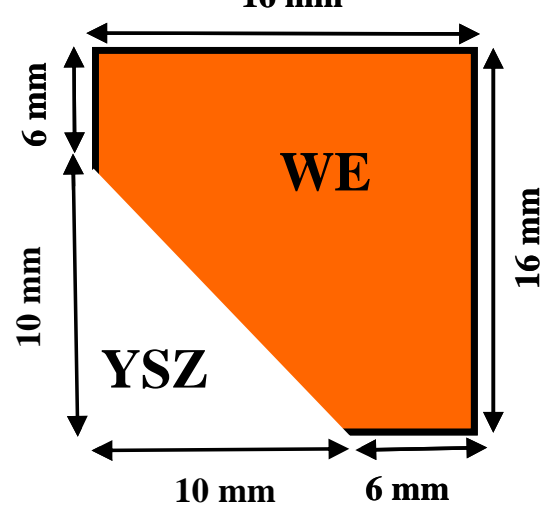

Figure 1 

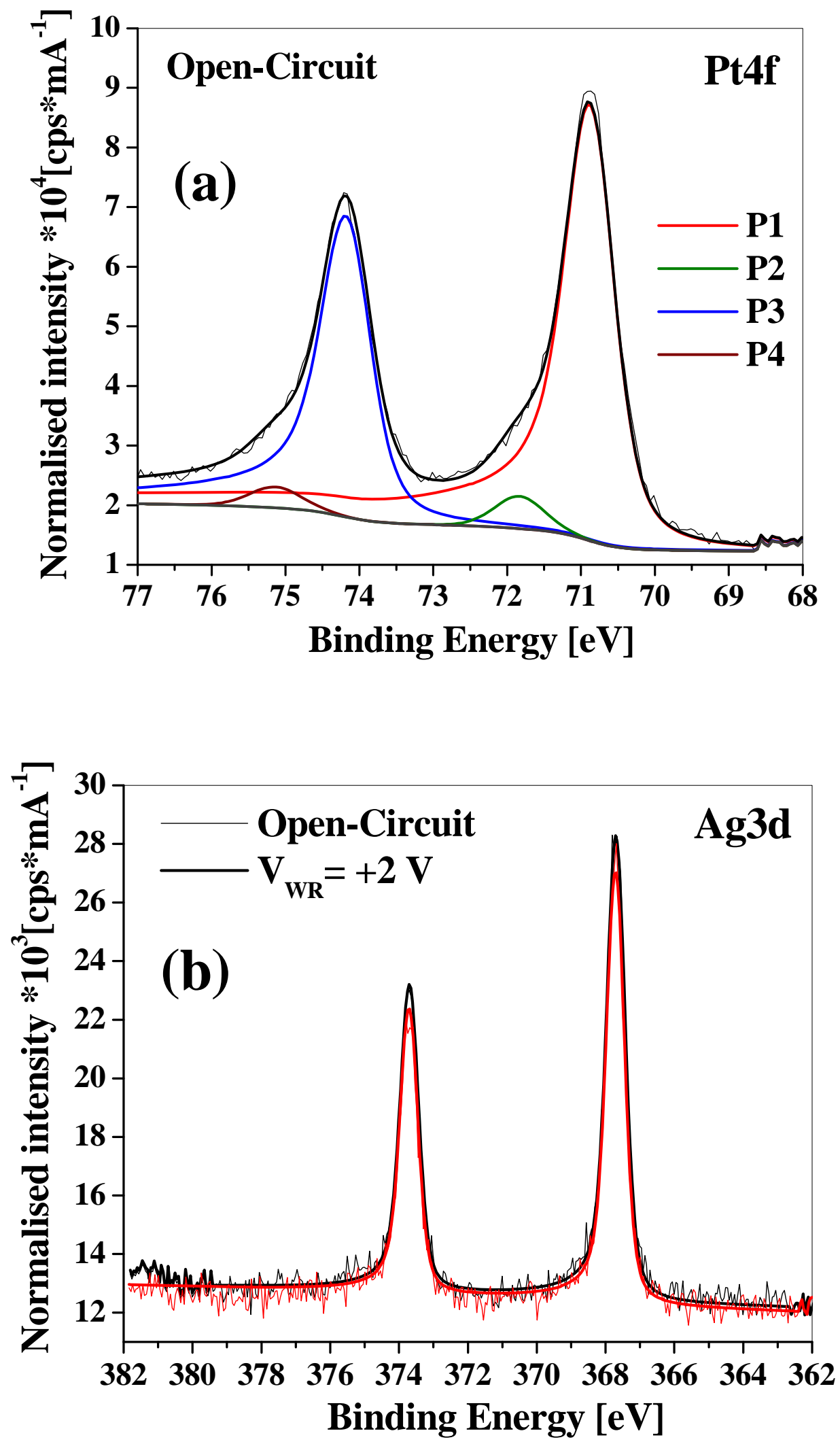

Figure 2 

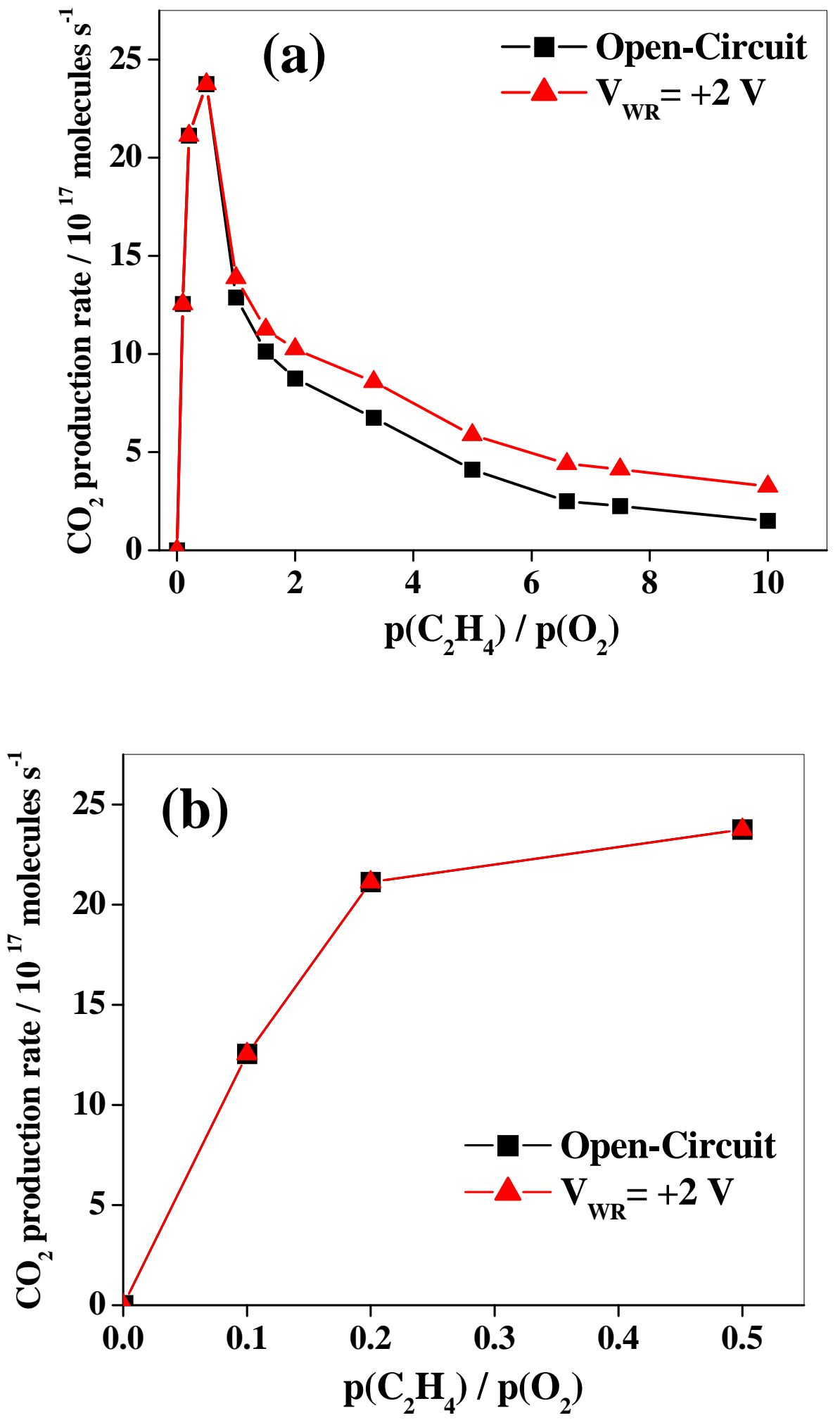

Figure 3 

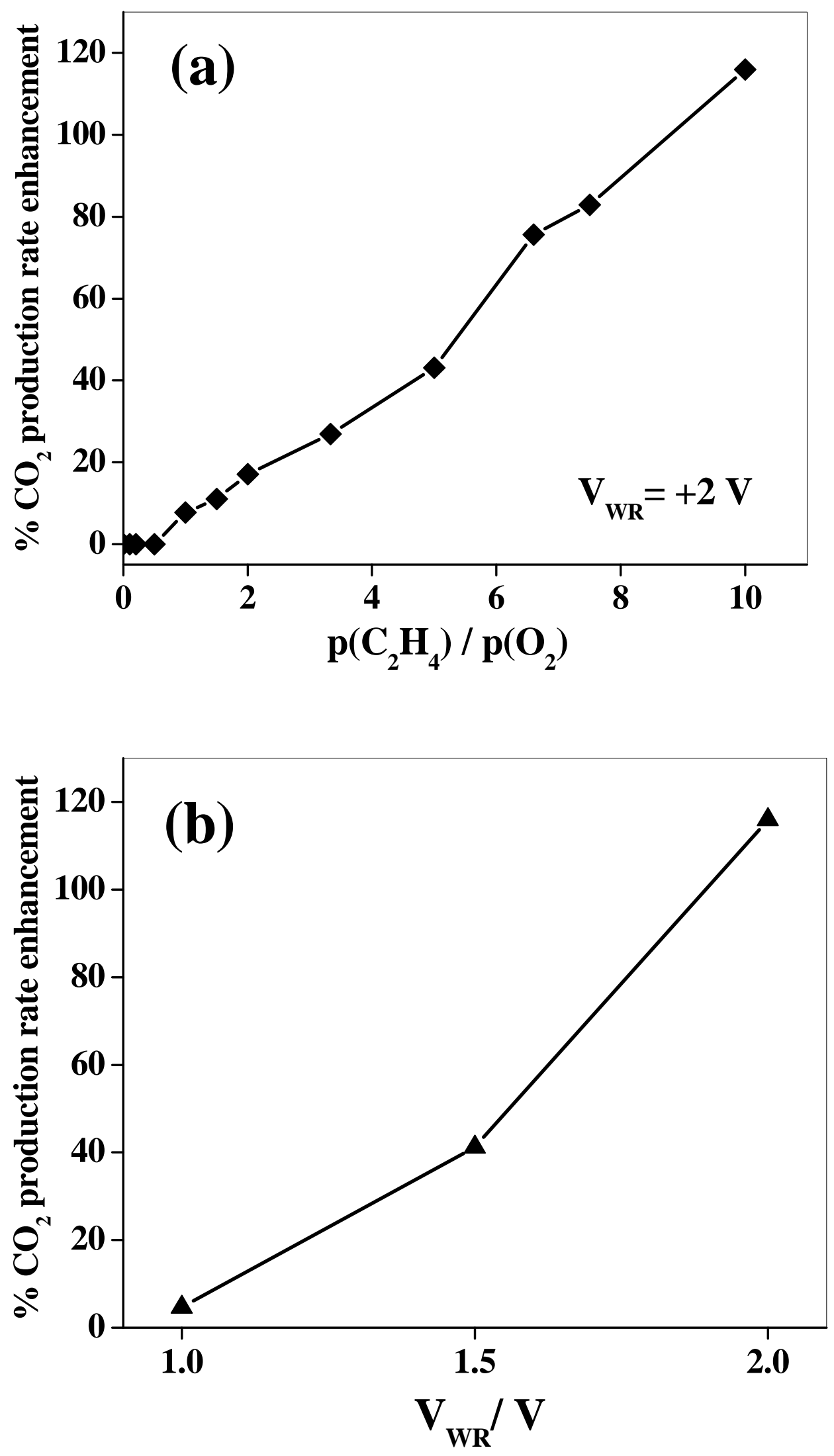

Figure 4 

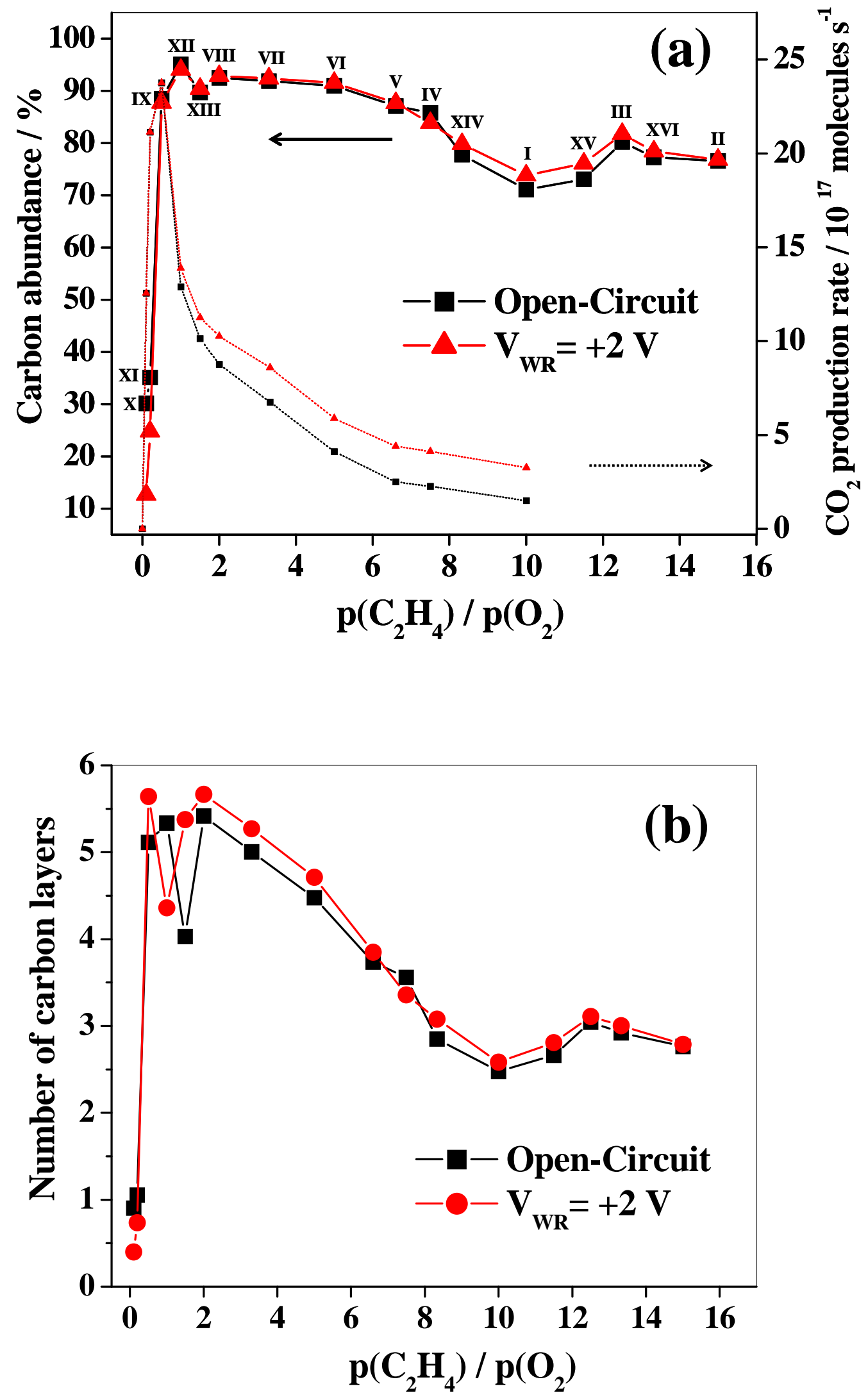

Figure 5 

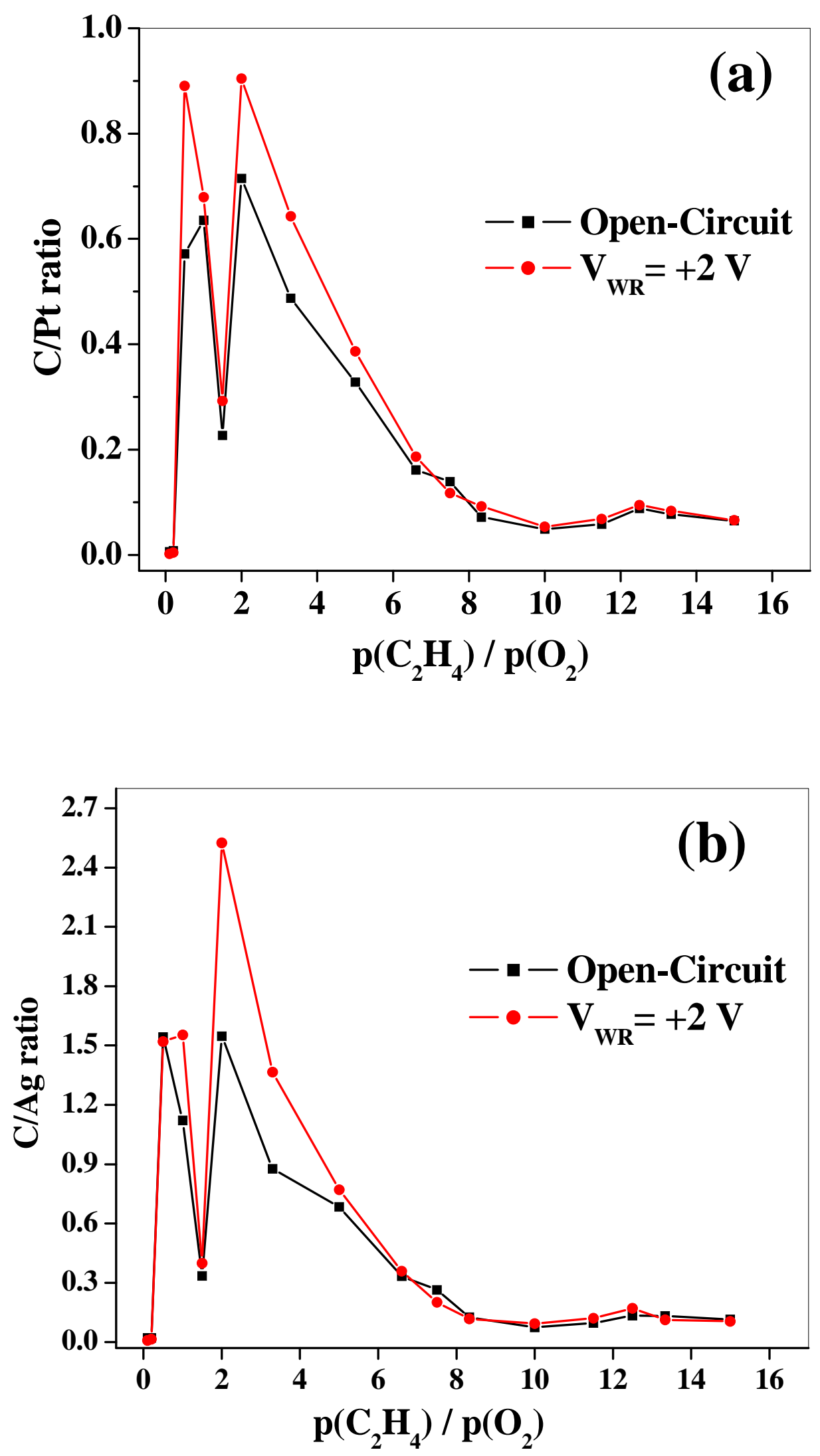

Figure 6 

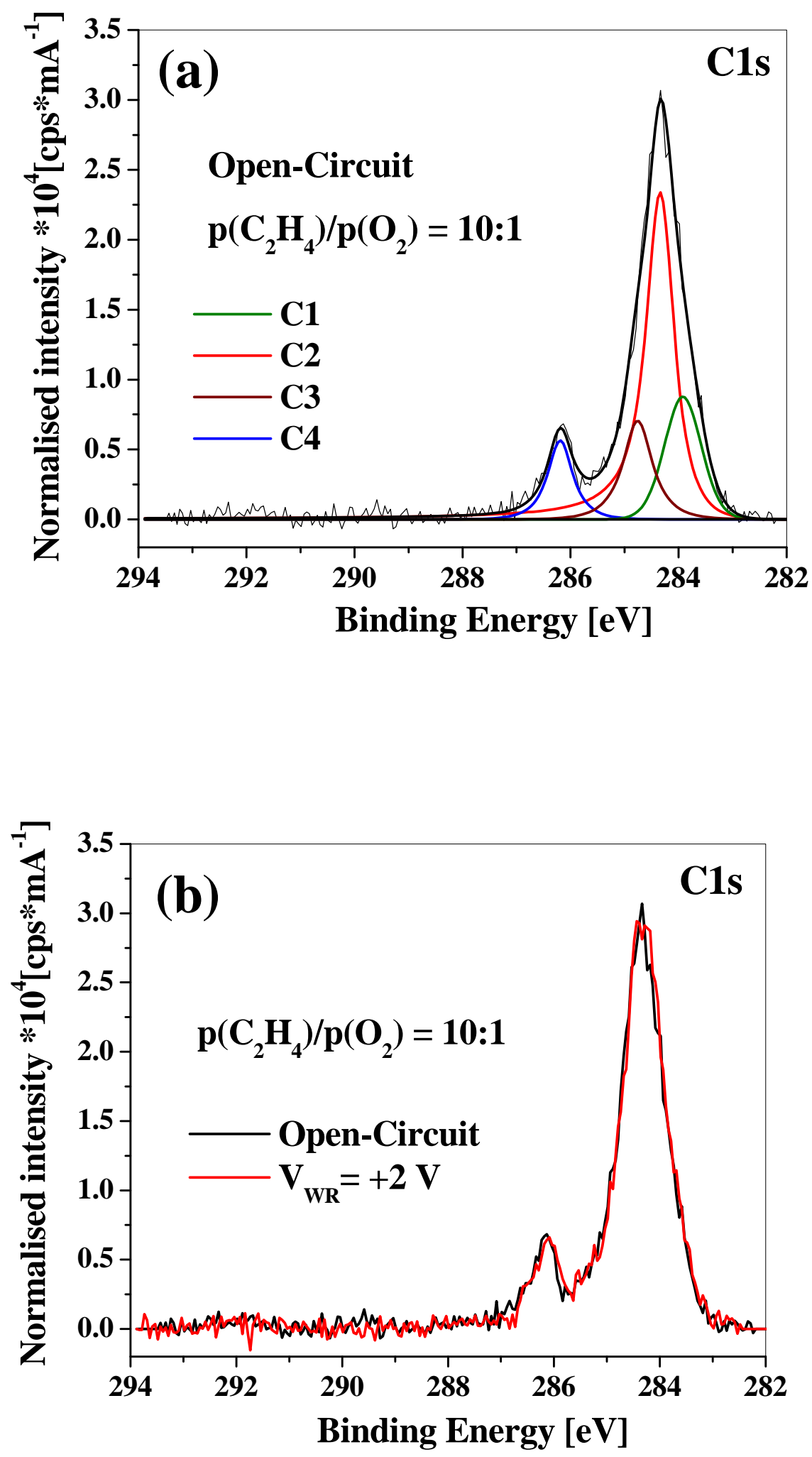

Figure 7a-b 

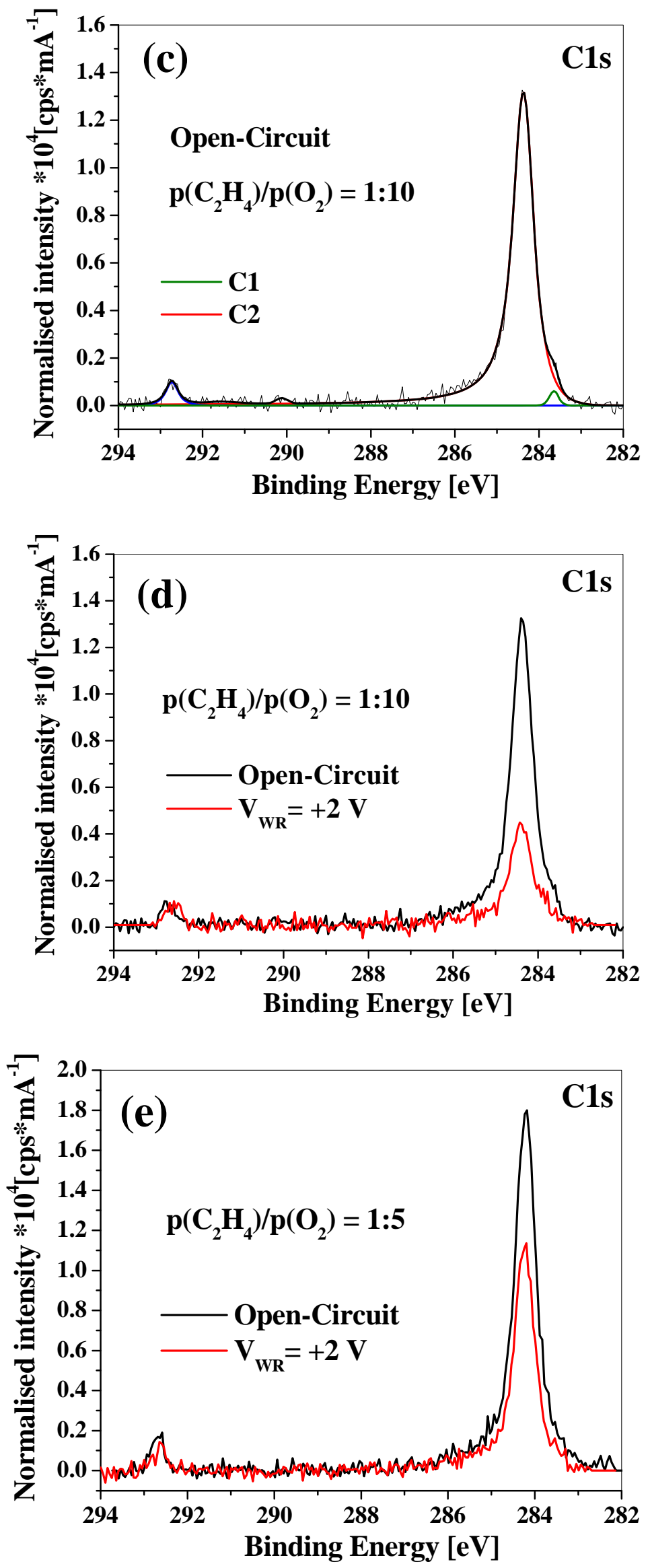

Figure 7c-e 

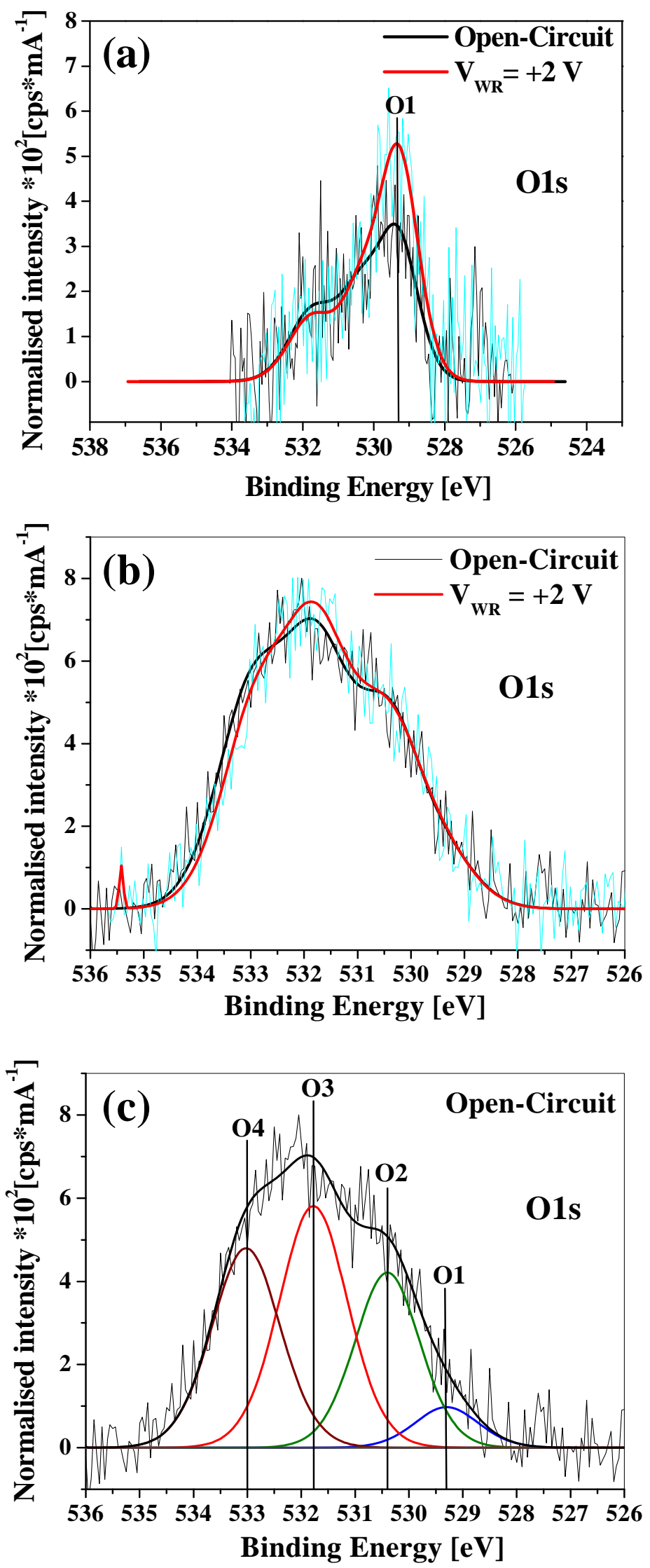

Figure 8 

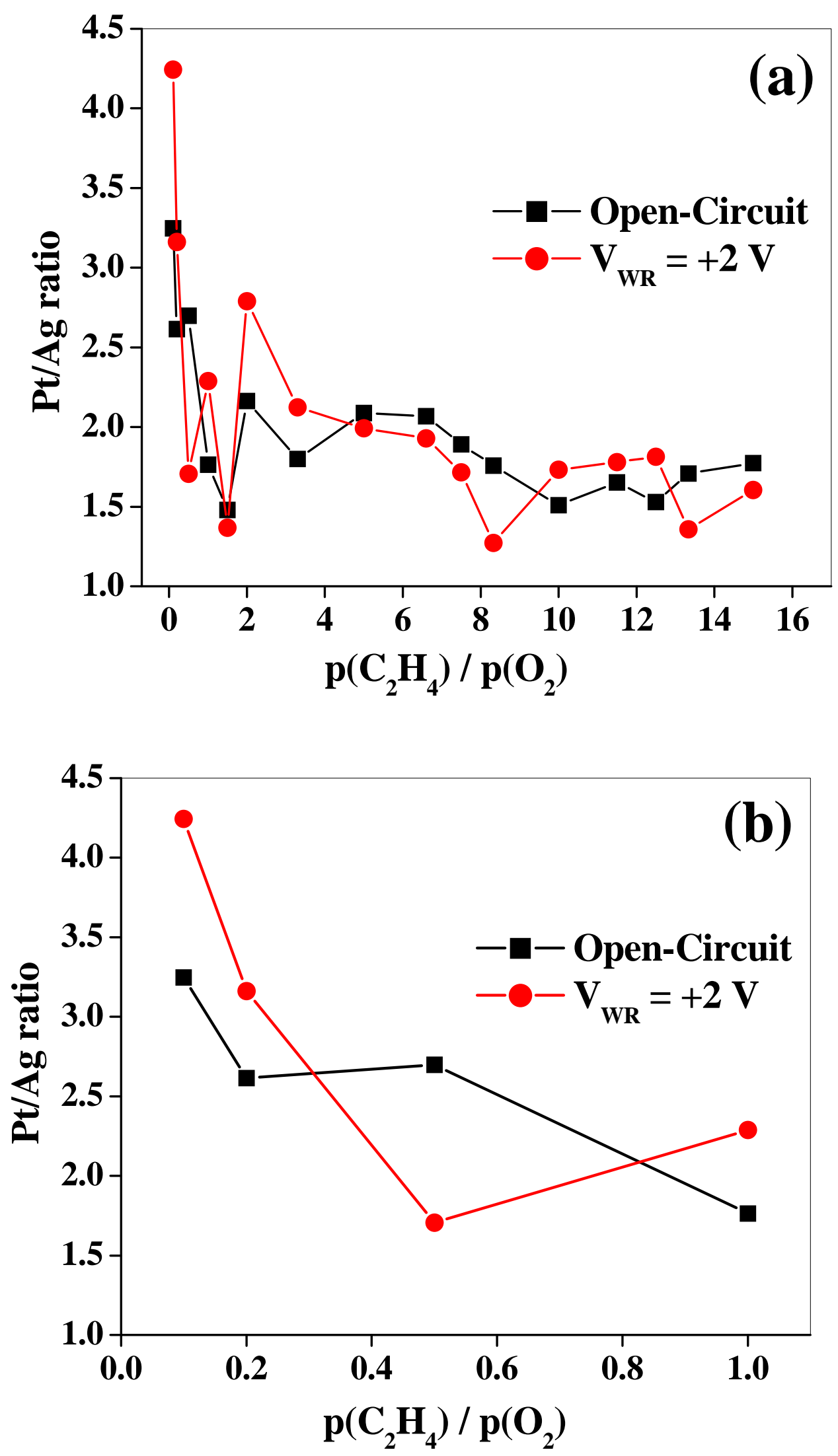

Figure 9 

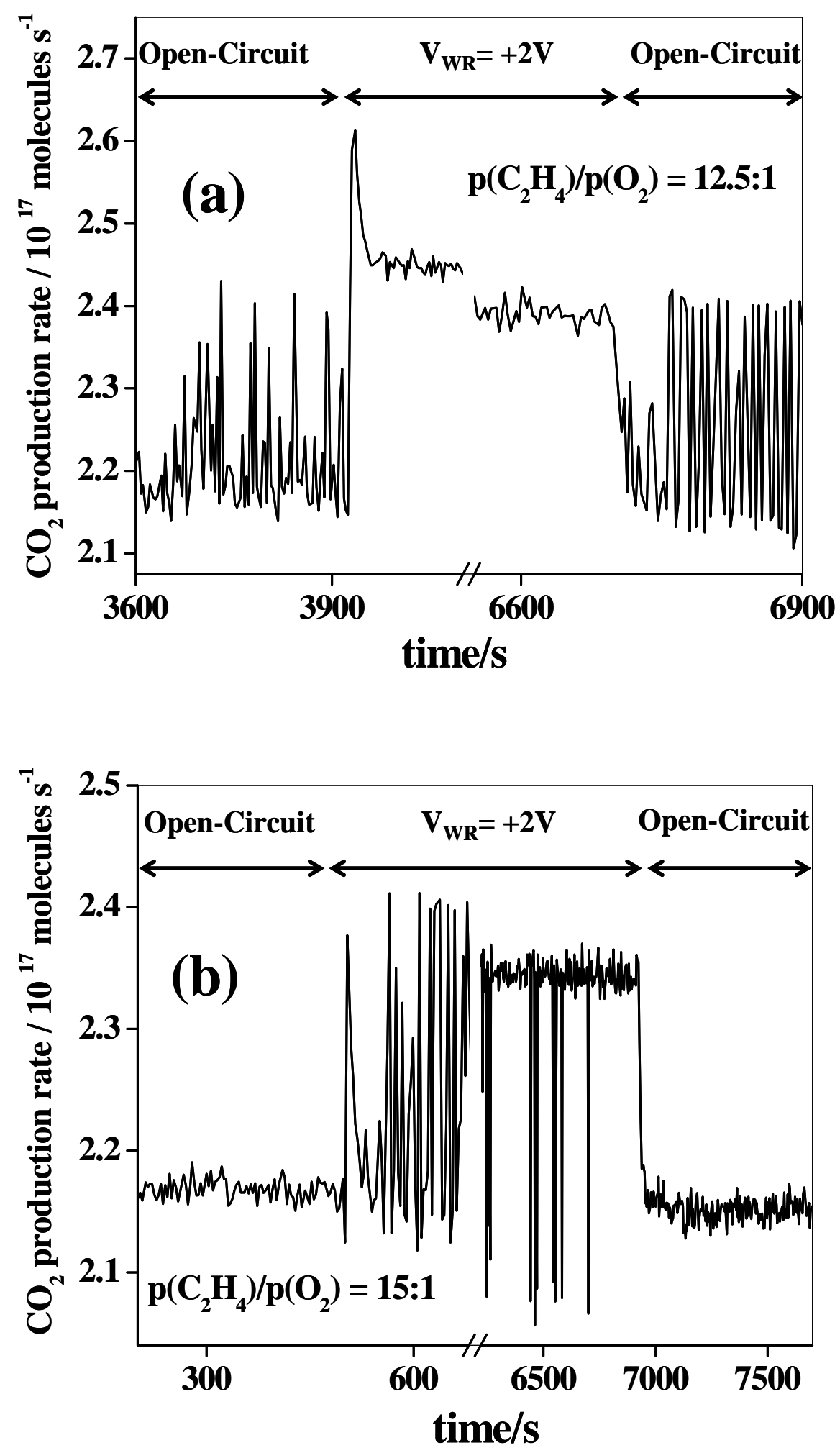

Figure 10 
(a) Oxygen in excess

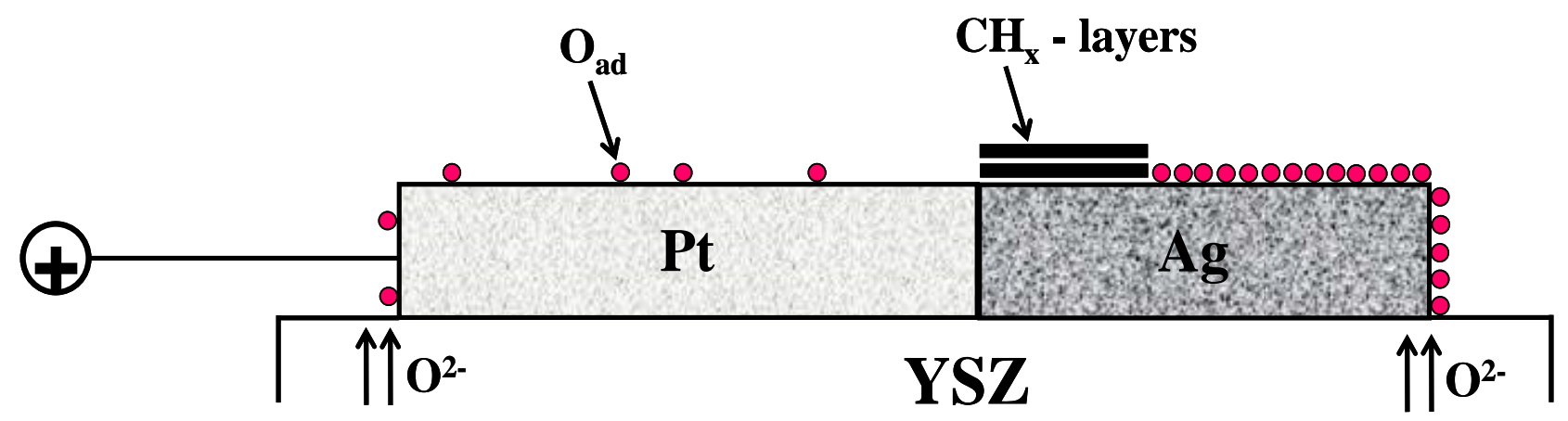

(b) Ethylene in excess

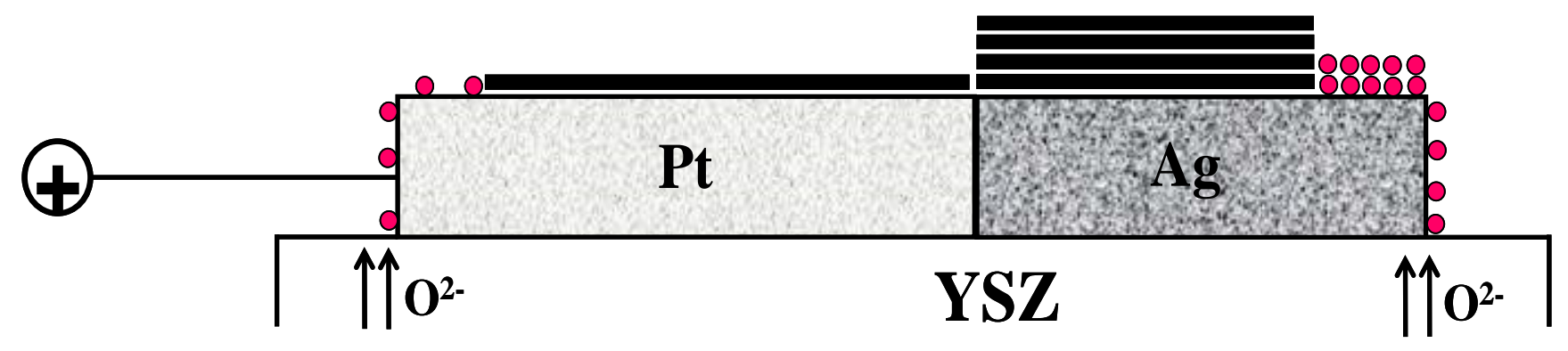

Figure 11 


\title{
Supporting Information
}

\section{Ambient pressure x-ray photoelectron spectroscopy during electrochemical promotion of ethylene oxidation over a bimetallic Pt-Ag/YSZ catalyst}

\author{
Arafat Toghan ${ }^{1}$, Rosa Arrigo ${ }^{2}$, Axel Knop-Gericke ${ }^{2}$, Ronald Imbihl ${ }^{1 *}$ \\ ${ }^{1}$ Institut für Physikalische Chemie und Elektrochemie, Universität Hannover, \\ Callinstrasse 3-3a, D-30167 Hannover, Germany \\ 2 Fritz-Haber-Insititut der Max-Planck Gesellschaft, Abteilung Anorganische Chemie, \\ Faradayweg 4-6, D-14195 Berlin, Germany
}




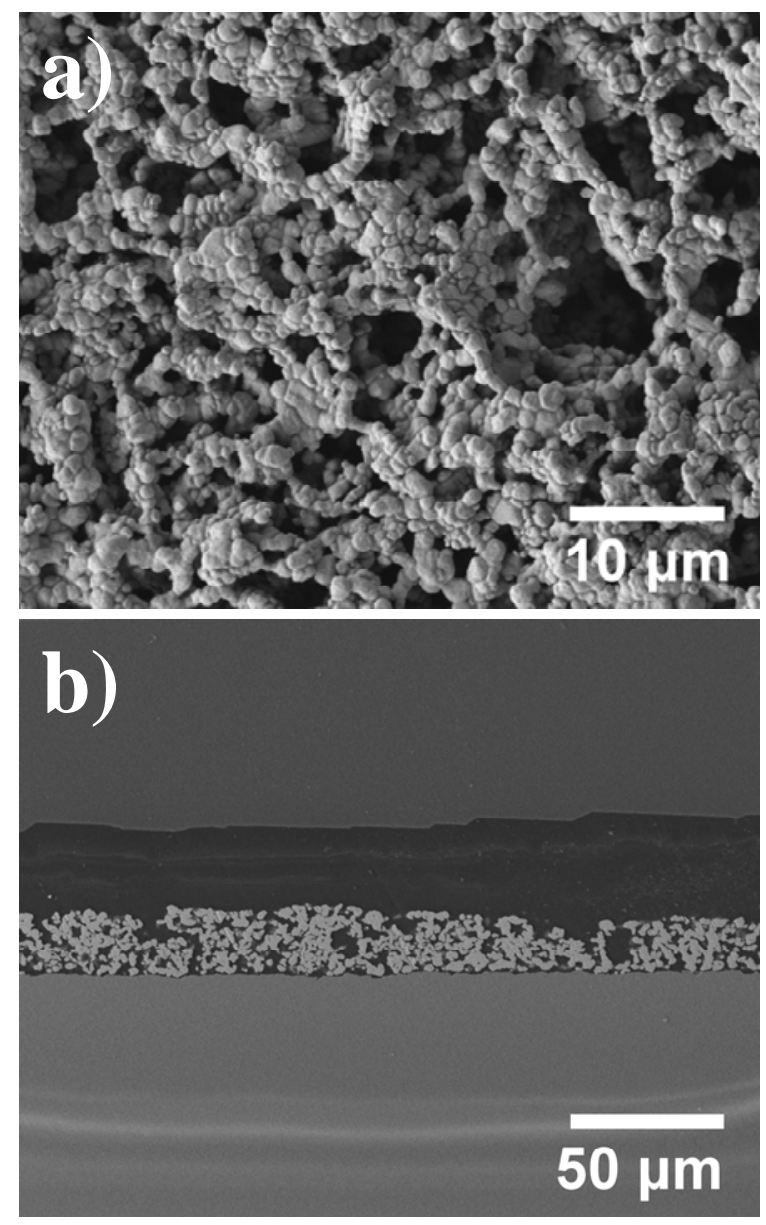

Fig. S1. SEM micrograph of a Pt/Ag WE electrode on a YSZ (111) single crystal after annealing for $3 \mathrm{~h}$ in air at $1120 \mathrm{~K}$. (a) Top view, and (b) Cross section. 

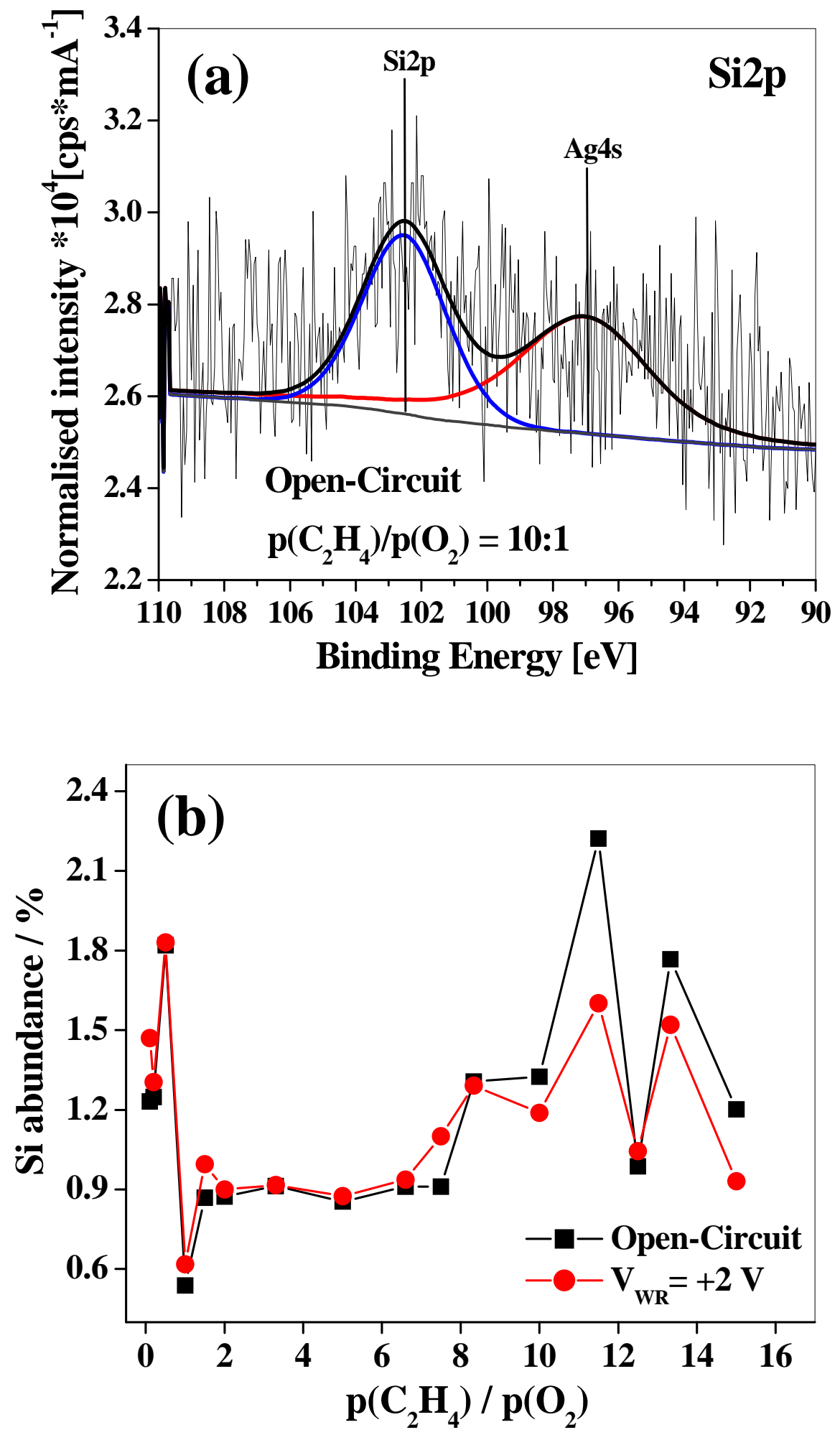

Fig. S2: (a) Si2p spectrum under OC conditions for a $\mathrm{p}\left(\mathrm{C}_{2} \mathrm{H}_{4}\right) / \mathrm{p}\left(\mathrm{O}_{2}\right)=10: 1$ ratio at 0.25 mbar and $\mathrm{T}=650 \mathrm{~K}$. (b) Variation of the Si concentration during the EPOC experiment displayed in Fig. 3. The photoemission spectra indicated as only remaining contaminants $\mathrm{Si}$ after several cycles of cleaning and during variation of $\mathrm{p}\left(\mathrm{C}_{2} \mathrm{H}_{4}\right) / \mathrm{p}\left(\mathrm{O}_{2}\right)$ ratios. 

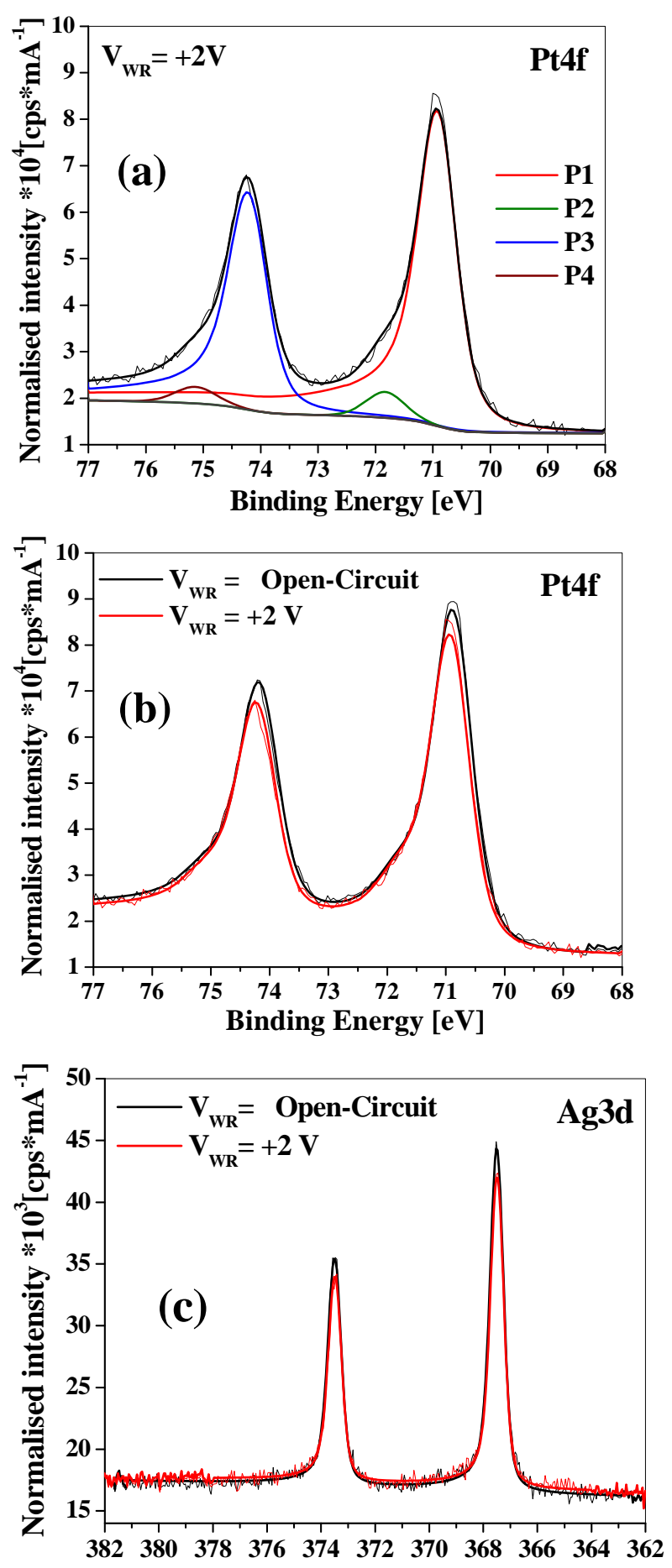

Binding Energy [eV]

Fig. S3: Photoelectron spectra characterizing the bimetallic $\mathrm{Pt} / \mathrm{Ag}$ catalyst under reaction conditions at $\mathrm{T}=650 \mathrm{~K}$ and $\mathrm{p}$ (total $)=0.25$ mbar. (a) Pt4f spectrum for $\mathrm{p}\left(\mathrm{C}_{2} \mathrm{H}_{4}\right) / \mathrm{p}\left(\mathrm{O}_{2}\right)=10: 1$ with an applied electric potential of $2 \mathrm{~V}$ and with the different contributions P1-4 indicated (see section 3.1). (b) Comparison of the spectra under OC conditions and with applied potential $\mathrm{V}_{\mathrm{WR}}=2 \mathrm{~V}$ for the same 10:1 ratio presented in (a). (c) Ag3d photoelectron spectrum with oxygen being in excess, i. e. $\mathrm{p}\left(\mathrm{C}_{2} \mathrm{H}_{4}\right) / \mathrm{p}\left(\mathrm{O}_{2}\right)=1: 5$. Comparison of the spectra under $\mathrm{OC}$ conditions and with an applied electric potential of $2 \mathrm{~V}$ 

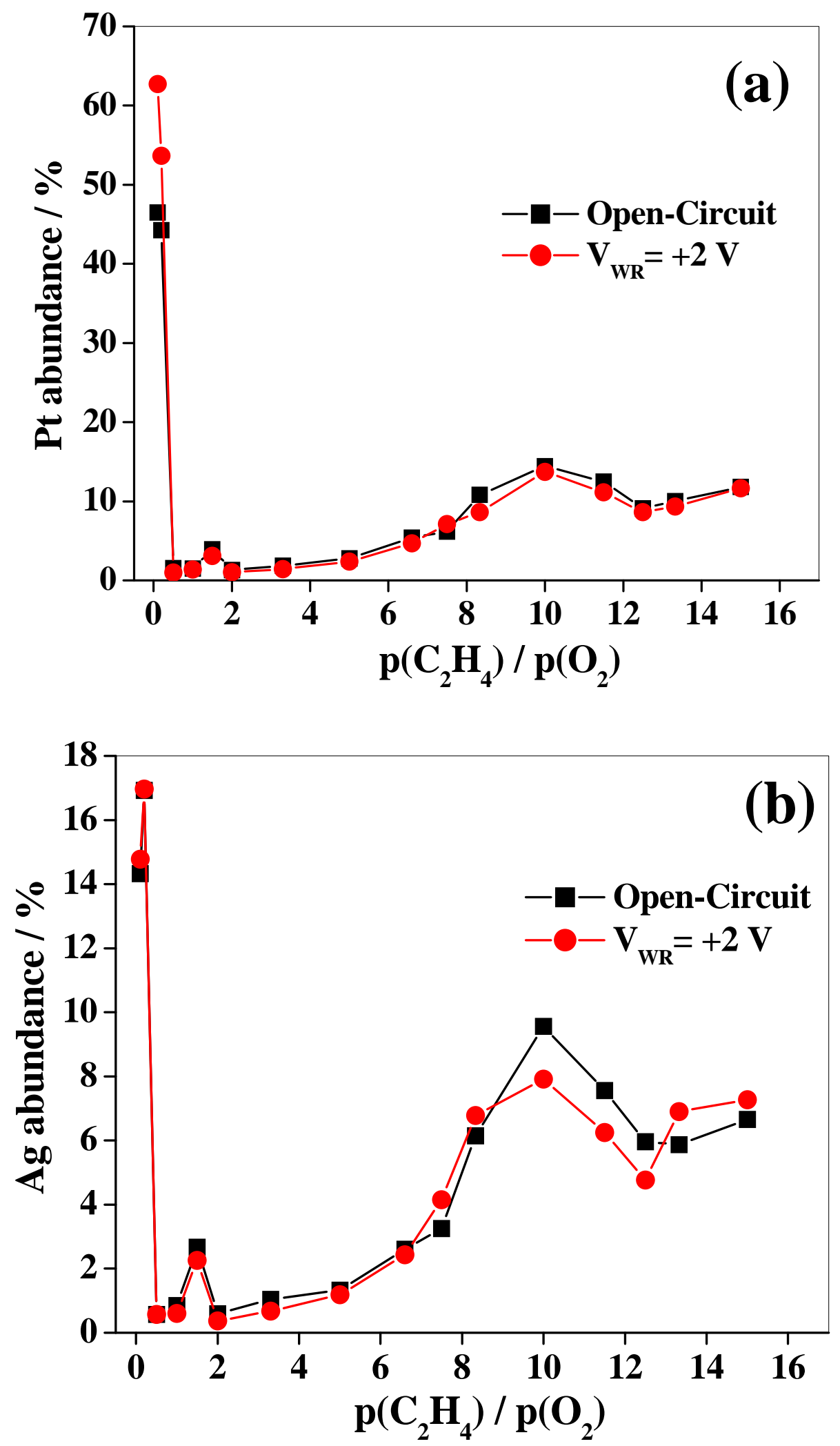

Fig. S4: Variation of the Pt and the Ag concentrations during the EPOC experiment displayed in Fig. 3. The application of a potential before the rate maximum removes preferentially carbon from $\mathrm{Pt}$ sites i.e. the carbon observed before the rate maximum is attached to $\mathrm{Ag}$ sites. The different amount of carbon over Pt and $\mathrm{Ag}$ sites causes a different damping of the metal signal as $\mathrm{p}\left(\mathrm{C}_{2} \mathrm{H}_{4}\right) / \mathrm{p}\left(\mathrm{O}_{2}\right)$ is varied. 


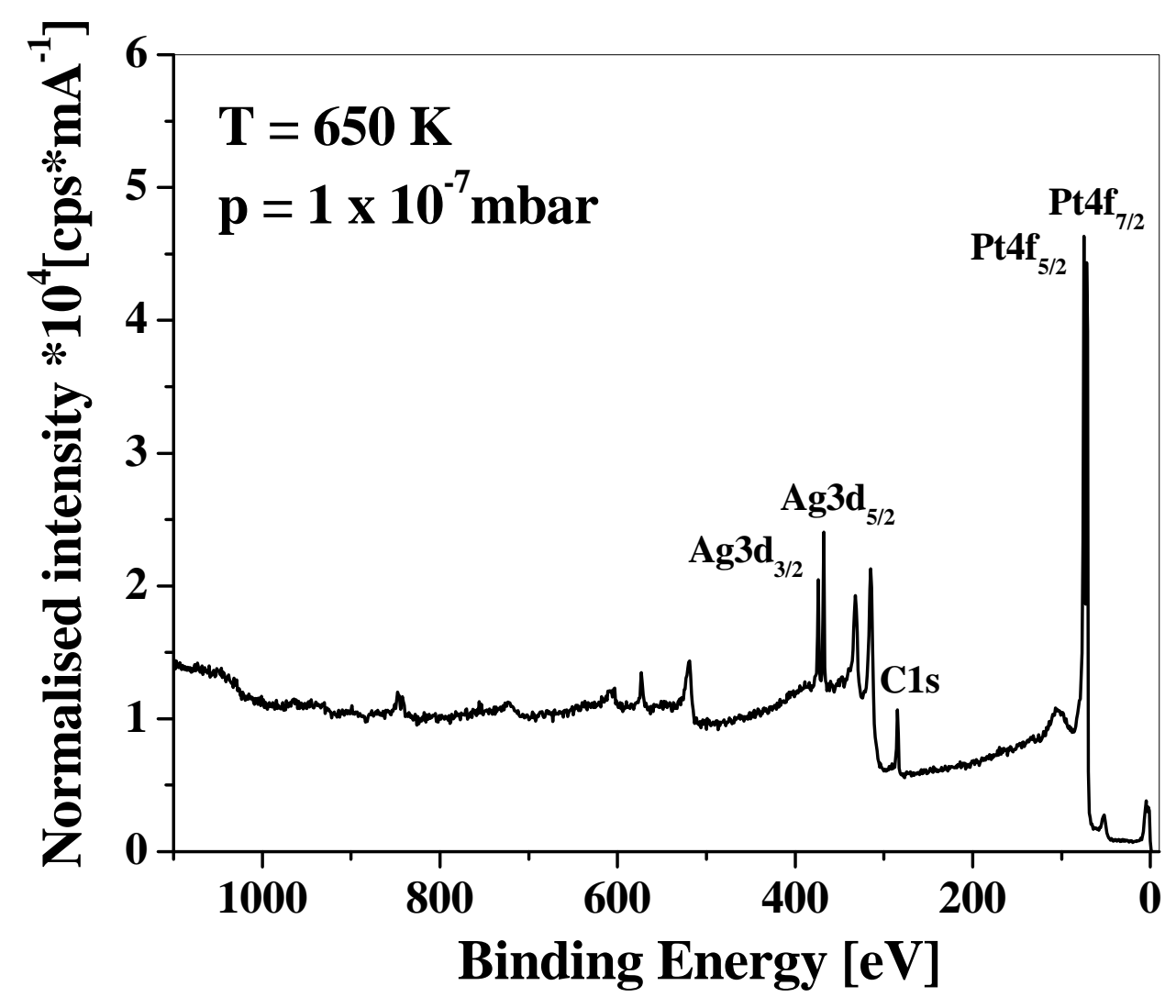

Fig. S5: XPS survey spectrum for Pt/Ag catalyst deposited on YSZ recorded prior to the EPOC/XPS experiments but after several cycles of cleaning. The Pt/Ag WE surfaces were cleaned by repeated cycles of mild $\mathrm{Ar}^{+}$ion bombardment $((\mathrm{T} \approx 400 \mathrm{~K}$, $\mathrm{E}=1.5 \mathrm{keV}, \mathrm{p}(\mathrm{Ar})=1 \times 10^{-4} \mathrm{mbar}$ and $\mathrm{t}=20 \mathrm{~min}$. $)$. 